\title{
THE CHALLENGING PARADIGM OF INTERRELATED ENERGY SYSTEMS TOWARDS A MORE SUSTAINABLE FUTURE
}

\author{
N. Soares ${ }^{a, b, c}$, A.G. Martins ${ }^{c, d}$, A.L. Carvalho ${ }^{e}$, C. Caldeira ${ }^{a, c}$, C. Du ${ }^{a, c}$, É. Castanheira ${ }^{a, c}$,

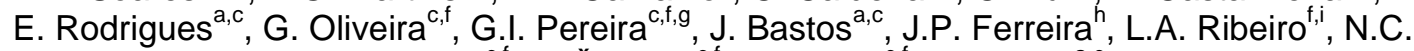
Figueiredo $^{\mathrm{c}, \mathrm{f}}$, N. Šahović ${ }^{\mathrm{c}, \mathrm{f}}$, P. Miguel ${ }^{\mathrm{c}, \mathrm{f}}, \mathrm{R}$. Garcia ${ }^{\mathrm{a}, \mathrm{c}}$

\begin{abstract}
${ }^{a}$ ADAI, LAETA, Department of Mechanical Engineering, University of Coimbra, Pólo II, Rua Luís Reis Santos, 3030-788 Coimbra, Portugal

${ }^{\mathrm{b}}$ ISISE, Department of Civil Engineering, University of Coimbra, Pólo II, Rua Luís Reis Santos, 3030-788 Coimbra, Portugal

${ }^{\mathrm{C}}$ Energy for Sustainability Initiative, University of Coimbra, Pólo II, Coimbra, Portugal

d INESC Coimbra, Department of Electrical and Computer Engineering, University of Coimbra, Rua Sílvio Lima, Pólo II, 3030-290 Coimbra, Portugal

${ }^{\text {e }}$ Federal Institute of Mato Grosso, Campus Diamantino, Rodovia Roberto Campos, 78400-970 Diamantino, Brazil

${ }^{\dagger}$ INESC Coimbra, Rua Sílvio Lima, Pólo II, 3030-290 Coimbra, Portugal

${ }^{9}$ MIT Portugal Program in Sustainable Energy Systems, Massachusetts Institute of Technology, 77

Massachusetts Avenue, E18-430, Cambridge, MA 02139, USA

${ }^{\mathrm{h}}$ GOVCOPP, Faculty of Economics, University of Coimbra, Av. Dias da Silva, 165, 3004-512 Coimbra, Portugal

'Postgraduate Program in Architecture and Urbanism of the Polytechnic School at Faculdade Meridional (IMED), Passo Fundo, Brazil
\end{abstract}

\section{Abstract}

This paper brings together several contemporary topics in energy systems aiming to provide a literature review based reflection on how several interrelated energy systems can contribute together to a more sustainable world. Some directions are discussed, such as the improvement of the energy efficiency and environmental performance of the systems, the development of new technologies, the increase of the use of renewable energy sources, the promotion of holistic and multidisciplinary studies, and the implementation of new management rules and "eco-friendly and sustainable" oriented policies at different scales. The interrelations of the diverse energy systems are also discussed in order to address their main social-economic-environmental impacts. The subjects covered include the assessment of the electricity market and its main players (demand, supply, distribution), the evaluation of some urban systems (buildings, transportation, commuting), the analysis of the implementation of renewable energy cooperatives, the discussion of the diffusion of the electric vehicle and the importance of new bioenergy systems. This paper also presents relevant research carried out in the framework of both the Energy for Sustainability Initiative of the University of Coimbra and the Sustainable Energy Systems focus area of the MIT-Portugal Program. To conclude, several research topics that should be addressed in the near future are proposed.

\section{Keywords}

Electricity markets, Electricity distribution, Industrial ecology tools, Urban planning, Electric vehicle, Bioenergy systems 


\section{Contents:}

1. Introduction 3

2. Renewables and the sustainability of electricity markets 5

3. Electricity distribution adaptation to a smarter and more sustainable future 7

4. The potential of city scale residential demand response in the electricity grid 10

5. Renewable energy cooperatives and other citizens' power initiatives towards a community based distributed energy generation. 16

6. Input-output multi-objective models to assess economic-energy-environment policies .... 20

7. The potential of urban planning in reducing environmental and health impacts 23

8. Influence of commuting in the urban economies and the environment. 27

9. The importance of consumer preferences on the diffusion of electric vehicles 29

10. Factors influencing the environmental impacts of electric vehicle adoption 31

11. Challenges of emerging biofuel technologies 34

12. Sustainability of bioenergy systems 35

13. Conclusions 38

\section{Abbreviations:}

$\begin{array}{ll}\text { CBD } & \text { Central business district } \\ \text { GHG } & \text { Greenhouse gas } \\ \text { CRE } & \text { Community renewable energy } \\ \text { CSA } & \text { Commuting satellite account } \\ \text { DR } & \text { Demand response } \\ \text { DSM } & \text { Demand side management } \\ \text { DSOs } & \text { Distribution system operators } \\ \text { EE-IO } & \text { Inventories and environmentally extended input-output } \\ \text { EfS } & \text { Energy for sustainability } \\ \text { EIO-LCA } & \text { Economic input-output life-cycle assessment } \\ \text { EU } & \text { European Union } \\ \text { EVs } & \text { Electric vehicles } \\ \text { GVA } & \text { Gross value added } \\ \text { IO } & \text { Input-output } \\ \text { IO-MOLP } & \text { Input-output multi-objective linear programming } \\ \text { LC } & \text { Life-cycle } \\ \text { LCA } & \text { Life-cycle assessment } \\ \text { LCC } & \text { Life-cycle costing } \\ \text { LCSA } & \text { Life-cycle sustainability assessment } \\ \text { LMA } & \text { Lisbon metropolitan area } \\ \text { LUC } & \text { Land-use change } \\ \text { MCDA } & \text { Multi-criteria decision analysis } \\ \text { MRIO } & \text { Multi regional input-output } \\ \text { NRAs } & \text { National regulatory authorities } \\ \text { PV } & \text { Photovoltaic } \\ \text { REMS } & \text { Residential energy management systems } \\ \text { SLCA } & \text { Social life-cycle assessment } \\ & \end{array}$




\section{Introduction}

Back in 2006 a group of professors at the University of Coimbra decided to create a multidisciplinary Initiative designated Energy for Sustainability (EfS). Its roots were the previous collaborations that had taken place in the context of joint supervision of PhD and MSc theses. These professors found out there was a great deal of common scientific interests among them and a significant potential to carry out new scientific projects and contracts with industry, as well as new postgraduate interdisciplinary educational programmes. The implementation of a Master and a PhD programmes followed shortly, in 2007, after approval by the University Senate, which included the formal recognition of the existence of the EfS Initiative. The number of professors involved grew progressively along the decade from the original 20 to 100, plus those post-doc researchers that, after obtaining the PhD degree, remained at the research units where they participate in project teams or lead those teams.

The EfS Initiative is, by option, based on the research units where the professors and other researchers perform their activities. The backgrounds are very diverse, covering all the classic engineering fields (civil, mechanical, electrical, chemical), computer science, psychology, architecture, economics, life sciences, sociology, law, earth sciences, represented by 15 research units. For all purposes, the Initiative acts exactly on the same grounds as the University itself. The EfS Initiative is the University's frontend for the wide interdisciplinary area of energy for sustainability: it manages scientific research, post-graduate studies and industrial liaison though contacts with companies. A fourth stream of activity is also organised, towards the sustainable management of the University campuses. In 2012, the University recognised the role the EfS Initiative had been playing as an actual institutional front-end. The Initiative was then officially considered a strategic institutional project directly depending from the University's Rector, with a statute published in the official journal.

Scientific research is always carried out at the research units, which are responsible for all the activity, as they own and administer the corresponding funding. There are no overheads charged by the Initiative which, on the other hand, cares to facilitate the whole path towards ultimately signing a contract: identifying the funding opportunities, fostering the building up of multidisciplinary teams, help mobilising the university resources needed to support all the preparatory work, and actively participate in the dissemination of the research results. A similar approach is used regarding industrial connections. 
On one hand, a yearly meeting is organised with a set of partners comprising more than 30 companies, the energy regulator, and the Portuguese energy agency. In this meeting the partners get in touch with the current research, visit a research unit, contact the students working on their theses, mainly through a poster contest and exhibition, and meet with faculty and researchers to discuss the next year roadmap. On the other hand, bilateral meetings with companies are frequently organised, either at the company's premises or at the university, where topics of common interest are identified and possible cooperation paths are envisaged, either in the area of education and training or in any interdisciplinary research stream that may reveal of usefulness to the company.

Sustainable campus activities are carried out through numerous projects where students are involved, mainly directed at the energy efficiency improvement in University buildings. This can involve energy audits, building up energy efficiency plans [1], modifying and upgrading building management systems [2], improving the efficiency of energy systems within buildings or the internal environmental quality, in cooperation with the University's facilities management service. A proposal was specified to implement a campus sustainability management system [3].

Educational activities include a PhD programme on Sustainable Energy Systems, operating in cooperation with two other Universities, a WSc programme and a post-graduate diploma on Energy for Sustainability, all having begun in $2008 / 09$, and a distance learning programme on Sustainability at Local Level, beginning in 2017/2018. The programmes were designed following a structured design approach described by Batterman et al. in ref. [4]. PhD students are encouraged to have two supervisors of different scientific backgrounds, in order to foster interdisciplinary work. The first PhDs graduated in 2013. Since then, 22 PhD graduated until May 2017. The first MScs graduated in 2010 and 62 graduated up to February 2017. Many of the young PhD researchers graduated within the Sustainable Energy Systems programme are spread throughout the world, in companies and research institutions. The ones that chose to remain at the University of Coimbra are presently a very important research working force, multidisciplinary as expected, who care to actively contribute to knowledge advancement.

The present paper, besides being a showcase of many issues on energy for sustainability, gathered together for a wide and structured view on contemporary issues, also shows how the diversity of competences grew among young researchers [5], as a result of the existence of the $\mathrm{PhD}$ 
programme and the intrinsic fertility of the co-operative multidisciplinary environment it requires to operate. This paper presents several subjects on energy systems towards a more sustainable future. The main goal is to analyse the major social-economic-environmental impacts of the interrelated energy systems under investigation. This paper also aims to provide an updated literature review on the covered topics, pointing out some areas of research that should be addressed in the near future.

\section{Renewables and the sustainability of electricity markets}

Many electricity reforms in Europe are being implemented since 1990. In pursuit of economic efficiency and greater competition, a single energy market is gradually being implemented in Europe, largely dependent on the development of adequate interconnections and cross-border transfer rules. The implementation of cross-border implicit auctioning mechanisms (market splitting/coupling) was paramount in the convergence of electricity spot market prices, contributing for the European integration of electricity markets. The emergence of substantial amounts of intermittent renewable generation, in particular from wind and solar, resulting from strong financial support mechanisms, reduces dependency on imported fossil fuels and allows GHG emissions mitigation. This was seen mainly in Europe, but was also observed in Australia and the USA, with wind based generation having the highest growth from $48 \mathrm{GW}$ in 2004 to $433 \mathrm{GW}$ in 2015 of global installed capacity [6]. Simultaneously, electricity markets and related liberalization are also observed in some other regions of the world. Nevertheless, with targets of renewable consumption share set to $45 \%$ for 2030 by the $\mathrm{EU}$, the increasing deployment of renewables in some European electricity markets creates demanding challenges to the electricity sector and some concerns are raised about security of supply and efficient system balancing.

It is demonstrated that the effect of renewables on spot electricity markets, given their almost null marginal costs, is to decrease wholesale electricity prices [7]. In the so called "merit order effect", low marginal cost renewables displace, for each spot market period, the aggregated supply bid curve to the right, reducing dramatically the residual load assigned to technologies with higher marginal costs. Therefore, spot electricity prices decrease and the market fails to provide correct signals to sustain adequate generation capacity, configuring the "missing money problem". Nevertheless, this does not mean that the decrease in spot electricity prices originates a reduction of electricity price to 
the end consumer, as the costs associated to incentives given to renewable electricity producers are transferred to consumer tariffs and may not be completely offset by the spot electricity price decrease. This is currently the cause for a big political debate. Arguments about industrial competitiveness are exchanged, as the electricity costs and renewable incentives burden can cause, in extreme, companies to leave Europe.

Renewables integration into the electricity market requires market adjustments to overcome the identified failures. The "melting-pot" and "salad-bowl" concepts express two alternative routes for policy makers [8]. However, flexibility of the electricity system is fundamental to obtain an efficient electricity market. This flexibility can be obtained through a number of strategies, of which, regional market integration and demand response (DR) seem to be unanimously considered throughout the literature [9]. Electricity market integration is one of the fundamental requirements for the introduction of renewables into the electricity system, contributing for adequate levels of security of supply, whilst providing operational optimization of the generating infrastructure. However, it was demonstrated that the large renewable generation capacity deployment observed has a major influence on electricity price divergence among spot electricity markets [10-12]. The integration of renewables into the electricity spot markets can also benefit from the deployment of effective energy storage facilities, the possibility of wind power production curtailment and the expansion of transmission systems. Furthermore, to achieve renewables optimisation and growth, aiming to reach the desired EU target of $27 \%$ and keeping market integration out of peril, cross-border interconnection capacity recommendation should be increased beyond the currently discussed target of $15 \%$ [12]. Moreover, the internal development of dispatchable reserve capacity for balancing and grid security purposes can be avoided through the development of an adequate cross-border interconnection capacity [13]. Coordination of both interconnection development and renewable incentives should be considered by EU policies.

Policy makers and regulators aim to harmonise the electricity sector; however, the dynamics involved are difficult to predict and new challenges arise in designing adequate measures to provide information to electricity system stakeholders, to guide investment priorities, establish risks and provide guidance in policy design and regulatory framework. The development of eco-friendly and sustainable measures, recognising that the environment and its diminishing resources represent a genuine threat to long-term prosperity, are driving European policy. 


\section{Electricity distribution adaptation to a smarter and more sustainable future}

Electricity distribution networks are a central component in the electricity value chain, traditionally designed to allow electricity flows from higher-voltages upstream coming from fossil generation, toward low-voltage downstream distributed loads [14], [15]. However, this traditional role is evolving partly due to the growing diffusion of distributed energy resources in the form of distributed solar photovoltaic or wind generation, electricity storage, electric vehicles (EVs) and charging infrastructure, as well as the increase of information and communication technologies that contribute to better monitoring and control capabilities [16-18], which make distribution networks smarter. Additionally, recent policies are stimulating a shift toward cleaner energy sources and sustainable development. In the EU the climate and energy agenda aims to deliver ambitious goals for energy efficiency and renewable energy increases, and GHG emission reduction with specific targets toward 2020, 2030, and 2050 [19-21]. These are further supported by the Energy Union [22], and the recent Clean Energy for All Europeans package [23], with specific proposals for redesigning the electricity sector [24-26].

These technology and policy dynamics can be observed as drivers for a transition to a smarter and more sustainable electricity sector. In the EU, this transition builds on the structural changes brought by market liberalisation [15], [27], through which electricity distribution was established as a regional natural monopoly, mandated to act as a neutral market facilitator separated from competitive activities in generation and retail. In this context, the roles, and responsibilities of electricity distribution system operators (DSOs) have been significantly policy-driven, and their operations regulated by National Regulatory Authorities (NRAs) at the Member State level [28-30].

The observed changes represent possibilities for new tasks to be performed at the distribution level [31]. For instance, DSOs could become more active network managers by coordinating system flexibility made possible by the growth of distributed generation and smarter loads and enabled by the increasing levels of monitoring and control. Nonetheless, these possibilities lead to a series of challenges related to the extent to which DSOs should be involved in activities and services associated with a smarter and more sustainable electricity system, such as: promoting energy efficiency, DR and demand side management measures; deploying, owning, and managing EVs charging infrastructure; deploying, and owning smart meters; managing distributed generation; and handling growing amounts of data [32]. These areas have been recently presented as "grey areas" for 
DSOs in the future [33], [34]. This uncertainty is associated with: the need for DSOs to act as neutral market facilitators in a liberalised sector; the possibilities for some of these activities to be developed in a competitive market; and, the fact that DSOs have an operational scale and connected grid-users base that could position them as adequate providers for innovative smart grid services.

The regulated monopoly nature of electricity distribution further exacerbates the challenges associated with adaptation, given that DSOs must continue providing a reliable and affordable service, while going through the challenges of a changing sector. Considering these challenges through a network industry transformation lens calls for intertwined efforts to solve technological, institutional, and organisational issues underpinning electricity distribution adaptation [35], [36]. This triad is also valuable for organising research efforts shedding light into these challenges. Technological adaptation-oriented research has contributed with knowledge on the integration of electricity storage in distribution systems [37-41], integration of distributed generation sources from wind [42-44], solar [45-49], CHP [50-52], and micro-CHP [53-56], integration of EVs [57-60], integration of smart meters [61-66], implementation of DR [67-71], deployment of active distribution management systems [7276], and advanced grid monitoring and control [77-79], as well as the use of artificial intelligence methods [80-82], and machine learning applications [83], [84]. Institutional adaptation-oriented research has contributed with knowledge on the adaptation of the existing regulatory framework [8590], with analysis of different regulatory approaches, such as incentive regulation [91-93], and innovative methods to stimulate electricity distribution adaptation to smart grids [94-96], which often include regulatory recommendations for NRAs [97], [98]. In addition to a number of studies on the impact of regulatory frameworks on adaptation [99-103], the branches of research presented are but a sample of the ongoing progress aiming at a better understanding of the technological and institutional changes necessary to the transition towards smarter and more sustainable electricity distribution.

In this context, the organisational adaptation aspects of electricity distribution have been explored to a limited extent, despite the evident importance of facilitating organisational change and business model innovation as part of the energy transition [104-107]. Contributions from organisational adaptation-oriented research have focused mostly on the impacts of market liberalisation [107-110], whilst fewer efforts are visible on understanding the ability of DSOs to adapt to a smarter and more sustainable electricity sector [106], [111]. 
Exploring the organisational dimension of electricity distribution becomes more relevant as the importance of the social sciences and humanities gains momentum within energy research [112], [113], for which interest on individual behaviours and their potential can be observed as a growing field of study [5], [114], [115]. In this context, DSOs are complex technological and policy-driven businesses, for which a better understanding of their ability to adapt towards smart grids can contribute insights to ongoing policy debates [116]. This knowledge can shape future policies and electricity market designs to consider business model innovation opportunities and constraints. These go beyond technical aspects (such as the extension of distribution networks, and electricity distributed), and regulatory aspects (such as incentive models, regulatory approaches). Additional aspects to consider include complex sets of technical, and managerial capabilities; and resources whose characteristics and flexibility to adapt to a changing paradigm remain significantly understudied to this day.

In line with this, future opportunities exist to develop a body of knowledge focused on the adaptability of electricity distribution companies in a changing electricity sector. Possible approaches could focus on organisational capabilities, and how these are influenced by business characteristics (e.g.: ownership, connected consumers, unbundling type, technical characteristics, operational expenditures, capital expenditures, network length, electricity distributed, etc.) [117], [118], as well as market factors (i.e. sector structure, sector liberalisation, regulatory method, innovation policies, etc.) [119]. Additionally, it would also be valuable to explore how market factors and business characteristics influence the role of DSOs on engaging in innovation activities, transition to more digital operations, and smart grids diffusion.

Only a more detailed understanding of the organisational dimension of electricity distribution can contribute with valuable insights for the debate on business model innovation and electricity market redesign [22], [25], [120], [121]. This proposed research efforts combined with ongoing research on technological and institutional adaptation can facilitate the transition of electricity distribution to a configuration in which connected consumers reap the benefits of innovative technologies and cleaner energy sources, all part of a smarter and more sustainable electricity sector. 


\section{The potential of city scale residential demand response in the electricity grid}

The impact on the electricity distribution system of DR actions will result of changes in the electricity usage by end-use consumers in response to stimuli. DR is a designation used for programs that seek to take profit of price elasticity of demand to get short-term load reactions to price signals or to signals related to some kind of operational grid constraint. However, due to the dispersed and uncontrolled nature of the management of end-use appliances, estimating the energy and power output of the aggregation of a high number of consumers enrolled in a DR program requires a specific approach which can take into account the random nature of load response.

The electricity grid is one of the most significant technological achievements of the $20^{\text {th }}$ century and is considered by many the most complex system ever built. This remarkable infrastructure carries electricity to enable services now considered essential for living [122]. However, there is a need to continuously balance supply and demand throughout the day in real time. Over the years, utilities have made various cost-effective improvements to the generation and dispatch of electricity to maintain reasonably reliable and affordable service to evolving electricity demands. Today, utility companies must also address new societal and regulatory obligations - mitigating emissions of GHG in their energy generating facilities, combining the traditional energy generation processes with dispersed generation, renewable energies and energy efficiency measures/requirements. Renewable energy sources, energy efficiency related measures and grid operation programs, e.g. DR, must be integrated both into the network and in the market. The future of both the electricity grid and the market needs the coordinated actions of competing players - producers, suppliers, consumers, prosumers (consumers that also produce and/or sell and/or store energy) and energy service providers [123].

The management of electricity consumption is an important tool to balance demand and supply. Instead of strongly investing in new network infrastructures and installing more generators to operate during peak demand periods, with low load factors [124-126], it is possible to manage energy use in households, through the so called DR strategies [127]. In the smart grid context, new devices have been proposed to modernize electrical power systems, combining features of smart metering with Residential Energy Management Systems (REMS). According to Roe et al. [128], REMS are a combination of hardware and software that conducts monitoring, planning and control functions of 
energy uses within a dwelling. However, having such a resource requires an investment by the DSOs, the utility company and/or by the energy consumer.

Of the available renewable energy sources, the most likely to be used at a larger scale are solar and wind, both of which are non-dispatchable, irregular and difficult to forecast. Using current tools to manage load and supply fluctuations, it is possible to deal with the variability of renewables at low levels of implementation. However, an increase in penetration of renewables of $10-30 \%$ of the power supply capacity requires new resources to make the fluctuating supply match the also fluctuating load [129].

Another reason for the study of new tools to balance supply and demand is that transmission networks in Europe, due to new market mechanisms, are becoming a platform for increasing energy flows [130], [131]. In addition to this burden, technological advances require more energy to supply new appliances. Thus, the gap between electricity supply and demand is increasing in many countries [132], [133]. Conventional approaches to solve the referred problems are based on the expansion of the supply-side resources, even if only to serve as idle backup power. These are usually highinvestment solutions which are expected to operate for a very small fraction of time. An alternative approach is then to manage the energy consumption, in order to compensate fluctuations, avoiding the need of new, most of the times stranded, supply capacity [124-126]. Recently, Celik et al. [134] stated that while the impact of DR at the household level is well studied, it still needs to be further investigated at a larger scale, e.g. neighbourhood level.

The possibility to use load control techniques or, more generically, to manage resources in households, exists because consumers do not need energy by itself. Instead, they need energy services, e.g., lighting, hot water, cooling/heating, among others, which should be provided in the most efficient way. This idea is not new, and it was underlined more than 30 years ago by Schweppe et al. [135]. The possibility of having equipment managing household energy resources can provide significant changes that need to be studied. Former Demand Side Management (DSM), focused on improving the efficiency of electricity consumption in general, and DR programs focusing in Load Management (LM) were run and almost completely controlled by the load manager (utility company) while price response programs depended almost exclusively on the energy consumer [136]. The deployment of DR programs and the recent trend to use advanced smart meters require the 
assessment of their possible aggregated impact. For that purpose, the knowledge of the household consumption pattern (and its composition in terms of the individual end-uses) is fundamental.

DR is based upon the assumption that the several elements of the electric grid can communicate with each other their response to comply with the needs of the grid operation. Possible examples are: managing demand to deal with grid events, switching off appliances temporarily in order to cope with peak load situations, shifting loads in order to reduce losses and take more advantage of available renewable generation. If no doubts exist that DR can help optimize system operation, it is unclear whether it effectively reduces energy use from consumers, bringing energy savings and environmental benefits. Some DR activities may provide net energy savings while others do not. In an emergency situation, dimming lights in an installation during the required time will not mean they will consume more energy afterwards, but for other equipment (e.g. air conditioning) switching it off during a system event can lead to an increase in consumption after the event is over. A complete review and description of DR programs was performed by Albadi and El-Saadany [127]. Kostková et al. [137] provided an extensive review on load management methods, techniques and programs, theoretically described or practically used. Recently, Celik et al. [134] provided a review on residential load modelling in a single home and concepts of coordinating mechanisms for multiple homes.

Several simulations of load control have been presented by many researchers, using diverse techniques. However, as stated before, a deployment at a larger scale has been weakly addressed. The following works have addressed diverse methodologies and techniques to simulate REMS performance. Karnouskos and de Holanda [138] stated that if a REMS system can only be implemented with high technical and financial effort, only few devices can be controlled and the involvement of consumers with low power input is not profitable. The simulated infrastructure implemented an energy controller agent that continuously monitors the overall power generation and consumption with any deviation beyond a specific predefined limit result in a control action, thus balancing supply and demand. If the systems account higher consumption than generation, the energy controller agent tries to shed some devices or to start new generation resources. If instead, there is higher generation than consumption, the energy controller reconnects loads. The capacity to shift the demand of certain household appliances was quantified by Teng and Yamazaki [139] according to the cost of electricity from two electric power sources, the energy grid and renewable energy locally 
produced in the household. Commercial supply was considered, when in use, to represent a high cost option, while renewable energy was referred to as a low cost option. An open industry standard for system-level modelling called SystemC [140] was used to create a simulation framework to model a house equipped with several home appliances and a smart metering device. The proposed platform scheduled three working periods. The presented simulation reduced the household peak power consumption from $2.73 \mathrm{~kW}$ to $1.19 \mathrm{~kW}$ in a four hour period. A simulation tool regarding the optimization of the operation of household appliances using DSM strategies was presented by Gudi et al. [141]. The formulation problem was performed using particle swarm optimization, trying to automatically select which appliances will operate at each moment, adjusting energy usage and minimizing energy costs. The optimization results revealed a reduction of $19-21 \%$ in electricity energy costs for the consumer. Molderink et al. [142] used three techniques to create control structures for the simulation environment of REMS. Artificial neural networks were used to predict a daily local production, using the consumption pattern, micro combined heat and power generation. A second technique consisted in performing a global programming approach in order to minimize the mismatch between what was consumed (demand) and what was produced (renewable energy). A final approach consisted in using a linear integer program to optimize the control of equipment in households. Local prediction using artificial neural networks performed well for 39 residences, for a single day simulation. The authors concluded that it is possible to make a forecasting for a group of houses based on predicted heat demand.

Real time pricing and DR stimulated by higher penetrations of renewable energy were studied by Roscoe and Ault [143]. This study had as its premise the use of real-time pricing of electricity, providing consumers to be flexible but to retain overall control. Two main objectives were set, the first one consisted in assessing the likely financial benefits of such tariffs for consumers and for the power network in general, the second goal consisted of predicting possible problems with implementing realtime pricing, by examining the difficulty in predicting demand and setting prices. A time-domain simulation with probabilistic appliance events was developed, taking into consideration the percentage of all households with electricity load types, the average electricity demand $\mathrm{kWh} /$ house/day (for all houses), the average electricity demand $\mathrm{kWh} /$ house/day (households without gas) and the average UK electricity demand for 25 million households. The events were scheduled using Poisson distributions and were characterized by increments of a certain power value (e.g. 150W) and a 
temporal duration $(0.5 \mathrm{~h})$ which are switched on at times of lower energy costs provided by the need to sell renewable energy in certain periods of the day (excess production) and in order to balance demand and supply. The simulation was influenced by a process of delaying working cycles of electrical appliances and by price elasticity. This simulation estimated an 8-11 GW potential peak demand reduction for the United Kingdom, strongly depending on the level of assumed elasticity. The authors also concluded that many customers will perceive real-time pricing tariffs as better value than the fixed-price tariffs. This is suggested because, on average, simulated consumers on real-time pricing tariffs manage to use more energy, although paying less. This may explain why electricity suppliers may be unwilling to offer such tariffs, since their profits may be reduced. Finally, the authors recommend further work on demand-forecasting and the price-setting strategies.

Roe et al. [128] developed a discrete event simulation to study DR action in a household. The methodology of this simulation was divided into two steps. The first one delays controllable appliances so they are not used during the DR service time. The second step manages a stationary battery in order to help reducing residential power demand during DR request time (load reconnection). Each daily power demand was simulated 50 times for each scenario. Differences between simulations consist in slightly modifying appliance start times and in the number of controllable appliance events, in order to model random consumer behaviour. The study considered the simulated results to compute the REMS simple payback period regarding the resulting energy savings. The conclusions of the study revealed that the simple payback period was in the order of one year for a REMS equipped household with no stationary battery. With a stationary battery, the simple payback period was extended to over 10 years. The simulation presented by Zeilinger [131] tries, according to the author, to be as flexible as possible in order to cope with DR options, defining the end-use behaviour to perform the simulation of appliances. Therefore, the study separated the household appliances in groups. This way of thinking led the author to present a working methodology in which each appliance has a control unit installed that independently determines the need to influence the power consumption due to the current energy supply situation. This can also be used to analyze the demand flexibility of energy resources in households. Miguel et al. [144] presented a simulation for an hypothetical $20 \%$ deployment of a residential energy management system on the city of Coimbra, Portugal, based on the Energy Box concept [145]. The authors described a methodology that identifies the start of operating cycles of appliances and other loads on a given general load diagram, enabling the 
simulation of load shifting caused by the operation of residential energy management systems. The results show the release of almost $3 \%$ of the demand on periods of higher price, but also the occurrence of a pronounced peak during the night period, an occurrence which may need to be dealt with, and for which some solutions were proposed. The developed methodology used spot prices, as those referred to by Miguel et al. [146], by applying clustering algorithms to historical data, namely using a hierarchical method and a self-organizing neural network, to obtain clusters of diagrams representing characteristic daily diagrams of electricity price.

Future results of appliance-focused testbed projects aiming at identifying the price elasticity related behaviour of electricity demand will hopefully lead to a deeper understanding of the impact that DR may have on optimizing the power system management and increasing the share of renewable energy. Such understanding may provide the basis to evaluate DR under different circumstances, crossing demand and generation capacity and their respective variations during the year. The original question that prompted some of these works consists in finding how an investment in an infrastructure can be justified without knowing what could be its outcome. REMS equipment is supposed to provide the network operator with a set of standard flexible loads. Currently, many of DR studies deal with delays to the operation of appliances. Other additional possibilities include interrupting the operation of appliances, considering more types of loads, e.g. appliances dealing with thermal energy or EVs, and considering local renewable generation. The possible introduction of new peak demand periods in the diagram implies the need to take into consideration management strategies. This is strongly related with the willingness and the time availability of consumers for the DR actions that are considered. One possible management hypothesis would be the introduction of a random delay when defining the restart of the various end-use loads. Peak coincidence would thus be reduced and the resulting aggregated diagram would be smoother. A different possibility may imply the DSO to have some degree of control, imposing a queue in order to only enable the switching-on of controlled appliances at an established maximum rate. 


\section{Renewable energy cooperatives and other citizens' power initiatives towards a community based distributed energy generation}

In the $20^{\text {th }}$ century, power systems have mainly been built to accommodate central power plants, meaning large fossil fuel plants, nuclear plants and hydro power stations. The emergence of renewable energy technologies for distributed electricity generation and their increasing cost competitiveness with traditional means has slowly, since the 1980s, initiated a disruption in electricity markets. More and more distributed energy resources are being introduced into the power system. End-users are becoming not only producers but also active participants in network balancing operations. Although there is no single definition, a broad consensus is that distributed energy generation systems are small-scale units that are connected to the distribution grid. They usually have one or several strong local dependencies. They are connected to the distribution network, not the very high voltage transmission grid. The energy source is available locally (e.g. wind, solar, biomass, biogas, geothermal, ocean energy, hydro), the producers consume the electricity for their own needs and/or they are relatively small actors in the electricity market (e.g. a municipality, a cooperative, a private investor, a land owner) [147]. Community renewable energy (CRE) initiatives are one example of such actors, emerging across Europe in different forms, as a result of local traditions and possibilities at their disposal in accordance with the existing relevant landscapes (e.g. market structure, grid accessibility and rules, financial infrastructure, institutions and renewable energy policy measures, support networks [148]).

While the classical regime of energy provision usually involves highly centralized energy infrastructures with "end-of-wire captive consumers" [149], CRE initiatives, in most cases, constitute a substantially different socio-economic model of energy production, distribution and use. What distinguishes CRE initiatives from investor owned or government renewable energy projects is that, as enterprises, they belong to the Social Economy. This is a middle-path, or third sector, that lies between the private sector dominated by investor owned firms and the public sector dominated by state owned enterprises. Social Economy enterprises are characterized by association-based economic activities founded on a specific set of values. They are autonomous in management, and practice a democratic decision-making system, such as "one person - one vote" in the case of "traditional" cooperatives where, regardless of the number of shares, a cooperative member holds one vote in the general assembly. Their modus operandi is based on the principles of participation, 
empowerment, individual and collective responsibility and care for the community. Their aim is to provide a service to members and/or the community rather than solely generating profits and seeking financial returns, assigning primacy to persons and work over capital. Unsurprisingly, as such many CRE initiatives have sprung out of social-movements belonging to the "political left", harbouring antinuclear (such as Elektrizitätswerke Schönau in Germany) or self-sufficiency and local energy security sentiments (Sifnos Island Cooperative in Greece).

The success of CRE initiatives depend on the voluntary contributions, intrinsic motivations and collective action capacities of their members, including their skills, knowledge, leadership qualities, embodied sustainable development values and objectives, and enthusiasm for grassroots initiatives dedicated to protection of the environment [150]. The EU, in its Energy Union Package [22], encourages this niche in the energy transition effort through outlining a vision of an Energy Union with citizens at its core, where citizens take ownership of energy transition, benefit from new technologies, and participate actively in the market.

CRE initiatives established with the objective of developing and operating renewable electricity projects have attracted increased attention in sustainable energy transition literature over the past couple of years. Although there is no universally accepted consensus in literature, researchers infer varying degrees of community involvement in the CRE term [151]. One of the most commonly cited categorizations [152] is that community projects are considered as those with a high degree of direct involvement and decision-making influence of local people in the planning, installation and operation of a project, and/or where the benefits of a project are distributed through local job creation, contribution to local infrastructure regeneration, providing local education resources and sensitizing the local population to sustainable energy provision topics (in addition to the wider global contribution towards further renewable capacities accumulation). However, within this defined scope, CRE initiatives analyzed in literature still remain quite multifaceted, and a diversity of ownership models exists. Projects can be either completely owned by the community or developed in partnership with private or public sectors. Such ventures include many legal and financial models (local institutional landscape permitting) such as cooperatives, community charities, development trusts representing communities' interests, and shares owned by community based organizations [153]. 
Within the variety of institutional, legal and financial models utilized in setting up CRE initiatives, cooperatives constitute the organizational form that is the most common vehicle for citizens' active participation in electricity markets and influence exertion on local energy policies in continental Europe. They provide the institutional framework to involve citizens with political, social and financial aspects of renewable energy deployment, thus "democratizing" the energy sector [154]. Renewable energy cooperatives carry with them underlying social values and ethical principles. Those principles are voluntary and open membership, democratic member control, economic participation by members, autonomy and independence, education, training and information, cooperation among cooperatives, and concern for the community [155].

From the technology perspective, and resulting from local bio-physical conditions, solar PV and wind energy technologies have clearly been documented in the literature as the most extensively applied systems in renewable energy cooperatives [149]. Photovoltaics are particularly attractive because of their modularity, simplicity, high reliability, low maintenance requirements and short lead times. Those favourable characteristics can also be attributed to the case of on-shore wind energy, where the simplicity of the power generation process, the high reliability of the technology and the availability of service providers (in countries where many RE cooperatives are found today) facilitate its application. In addition, an increasing number of rural biomass farmers' cooperatives are documented in Austria and the South Tyrol province of Northern Italy [156].

CRE literature aims to classify the drivers and barriers for citizens' energy initiatives [156], [157]. They can be identified within the boundaries set by systemic factors (as classified in ref. [158]) that define the electricity market and renewable energy landscape in the countries where they operate. Such factors include the market structure, namely division of activities, generation, transmission, distribution, and retail, and the level of competition within them, or degree of monopolistic concentration. Indeed, the majority of CRE initiatives in Europe are based in countries where liberalization has lead to increased competition among retailers and unbundling of activities in the energy market. Namely, according to the European Federation of Groups and Cooperatives of Citizens for Renewable Energy (REScoop) [159], there are 2.397 CRE initiatives and renewable energy cooperatives in Europe (defined according to the REScoop as organizations operating "a business model where citizens jointly own and participate in RES and energy efficiency projects"). The overview of the REScoop membership structure reveals that the national counts of such enterprise is 
very disproportional. Almost 55\% of member entities are based in Denmark, Germany and Sweden while Greece, Portugal and Spain altogether are represented by only 18 initiatives in the REScoop Federation. The number of such enterprises in Central and Eastern European ("new") EU member states is negligible. Moreover, in countries where the liberalization of the energy market is a reality, CRE schemes are responsible for significant renewables' capacities, most prominently in Germany where they constitute nearly $50 \%$ of installed RES capacities [160], and in Denmark where $70 \%$ of wind power plants are owned by cooperatives and farmers [161].

Further systemic factors are the complexity of administrative procedures for building permits, the transparency of grid connection processes and their costs, the access to renewable energy project financing (e.g. banks willingness to provide loans or the financial potential of citizens to purchase shares in projects), the public opinion and support for renewables, and the knowledge about potential benefits of CRE schemes. In the context of the latter, several studies suggest that small-scale community-based wind power projects receive strong levels of support from local people [162-164], and that local opposition towards wind energy projects, the so-called NIMBY ("not in my back yard attitude"), has been reduced through local participation, participatory decision-making processes, and (equal or fair) distribution of economic benefits [165-168].

The existence of a legal framework under which CRE initiatives (such as renewable energy cooperatives) may be established as legal persons, the rules of economic association that it prescribes, the actors that may join it (individuals, municipal institutions, etc.), and tax status that it carries, will determine whether such enterprises can be formed in the specific local context, operate in accordance with their defined set of values, and secure the envisaged benefits for their members and local community. Finally, and most importantly, the stability of political and financial renewable energy support policy schemes is identified as paramount factor for the success of CRE projects, most prominently for the development of new initiatives. The 2014 reform of the German renewable energy act, for example, resulted in a significant decrease in the formation of renewable energy cooperatives in the country, dropping to 29 new cooperatives in 2014, as opposed to 194 newly registered in the country in 2011 [158].

Nevertheless, cooperatives have also been found to be resilient to crisis, thus making them sustainable in terms of longevity. Such resilience, resulting from the dedication, capabilities and values 
that drive their members has helped cooperatives adapt their business models to overcome sudden and adverse renewable energy policy support shifts [169]. The International Labor Organization [170] has underlined that renewable energy cooperatives - as enterprises with a triple bottom line: people, planet and profit - have great potential for contributing to development, and poverty and energy poverty alleviation. By making energy accessible and affordable they can improve productivity and living conditions. Moreover, they create jobs, including green jobs, particularly in rural areas.

\section{Input-output multi-objective models to assess economic-energy-environment policies}

The input-output $(\mathrm{IO})$ methodology is an interesting and flexible tool for the theoretical or empirical investigation of a wide range of applications encompassing the analysis of more aggregated or disaggregated systems, depending on the objectives of the study [171]. Indeed, IO analysis has been applied for a wide set of specific problems, such as inflation, transportation requirements, environmental pollution, depletion of non-fuel mineral resources, impacts on the employment [172175] at different micro and macro level of analysis (such as national economic planning [176-178]; regional planning [179]; analysis of a specific sector [179], [180]; and study of enterprise's economy [181-183]). Some extensions and combination of 10 models with other methods have been developed in order to extend their application to different topics and allowed modelling complex systems regarding economic and physical relations [184-186]. IO models have been modified for the explicit analysis of the energy sector (e.g. see [187-189]), whereas intrinsic features regarding economic activity, energy use and environment effects have led to extensions of 10 models that combine both environment and energy modelling (e.g. see [190-195]) and to analyze energy-economy-environment (e3) interactions (e.g. see [196-198]). As referred to by Faucheaux and Levarlet [199], the e3 models are well suited to address the complex interactions between the process of energy production and consumption, the economy and the environment. Examples of the extension of 10 models are the Economic Input-Output Life-Cycle Assessment (EIO-LCA) method, IO Hybrid models and IO MultiObjective Linear Programming (IO-MOLP) models.

The EIO-LCA method has been developed for the application of 10 analysis to Life-Cycle Assessment (LCA) [200-203]. The LCA methodology assesses the environmental impacts associated with the life-cycle (LC) of the product under study and has an important role in public and private 
environmental management [204-206]. The advantages of the EIO-LCA models over the standard LCA's come from the capability of capturing all the intra-sector flows (both direct and indirect) without "double counting", less resources and time requirements and inclusion of emissions caused by services and machinery ([202], [207], [208]). The main strength of ElO-LCA model compared to standard LCA's is to provide a more complete supply chain of economic activity needed to produce any commodity in the economy, therefore extending the boundaries of the analysis to the entire economy [201]. For that reason, as referred to by Jeswani et al. [209], this method can be viewed as a macro-level LCA covering the "cradle to gate" portion of the LC that is potentially more useful to support high-level (e.g. national) policy decision-making rather than for decision-making on specific products or processes. On the other hand, some limitations of EIO-LCA (also derived from the assumptions of the basic 10 model) can be identified: the model often assumes the same production technology for imported and domestic products; problems related with the homogeneity and linearity assumptions in which each sector produces a single commodity using a single technology; proportionality between environmental loads and economic flows for sectors with different characteristics; problems of aggregation; the use and the end-of-life stages are neglected; and problems regarding reliable and up-to-date data [201], [202], [210].

Nevertheless, production and consumption systems are best represented by a combination of bottom-up and top-down perspectives in a model that reveals the microstructure of the important parts of a product system and, at the same time, covers the entire economic system [202], [211]. As a result, hybrid methods have been proposed to combine process-based LC inventories and environmentally extended IO (EE-IO) inventories in order to use the strengths of both [212]. The term "hybrid" herein represents not only the integration of 10 and process based data, but also the combined use of both physical (process-based) and monetary (IO-based) data, which opens the possibility of combining environmental and economic aspects [209], [213], [214]. In the hybrid models the combination of physical and monetary units into the 10 matrices is made, in which new rows and columns are included for energy sectors, substituting flows in monetary units by flows in physical units [215]. The use of the hybrid IO formulation helps eliminating the effect of price distortion on the results, i.e. specifying the energy transactions in physical units in this hybrid formulation allows that the energy conservation conditions can be expressed as a set of physical relationships independently of the prices of energy [193]. However, as stated by Majeau-Bettez et al. [211], the lack of quantitative 
assessments of the presumed advantages of hybrid approaches relatively to LCA and EE-IO models may partly explain their slow adoption. Therefore, LC databases should also incorporate hybrid perspectives, rather than a strictly process-based approach. The inclusion of economic aspects in LC databases will allow the progressive compilation of hybrid inventories.

$1 \mathrm{O}$ analysis has influenced the early development of linear programming models as a result of the empirical programming needs [216], [217]. Several studies in using linear programming models coupled with the IO framework for different purposes are identified [218-224], as well as introducing environmental and energy (and combinations of both) objectives [225-227]. However, IO-MOLP models can better capture the real world problems and have been applied to study the impacts of national and regional policies on the employment, water pollution, energy requirements, $\mathrm{CO}_{2}$ emissions, foreign trade balance, etc. [228-231]. IO-MOLP models using hybrid frameworks and external expansions of the 10 model have been used to assess energy-environment-economic-social objectives [215], [232-234]. Some studies have developed MOLP models based on IO analysis incorporating explicitly the uncertainty treatment: Chang and Juang [235] and Chang [236] have applied a MOLP model with fuzzy coefficients in the objective function; Borges and Antunes [237] have developed a MOLP with fuzzy coefficients in the objective function and in the right hand side vector; Henriques and Antunes [238] have applied an MOLP model with interval coefficients in the objective function, the right hand side vector and also in technical coefficients. The IO-MOLP models are able to capture the complexity and conflicting nature of real world problems allowing obtaining insightful information that would not be possible to achieve with a separated application of both methodologies. However, there is a lack of studies integrating inter-regional IO models with MOLP, as well as inter-regional IO models with hybrid units and MOLP models for e3 analysis and incorporating uncertainty analysis. The development of those methodologies will be useful for the analysis of specific states or regions inside a national economy, whereas dealing with uncertainty sources in the scope of IO-MOLP models. Finally, there is a lack of studies using the IO-MOLP framework encompassing economic, energy, environmental (especially GHG emissions) and social (especially employment levels) spheres coupled with LCA estimates, which are useful for the analysis of specific energy commodities. The integration of LCA and hybrid IO-MOLP models allows incorporating different processes into the model and expanding the boundaries of the analysis to the entire 
economic system such that direct and indirect effects in an integrated- or country-basis analysis are accounted for [239].

\section{The potential of urban planning in reducing environmental and health impacts}

The demands of a growing population and the increasing migration of population to urban areas, together with technology developments and lifestyle trends, have driven cities to rapid development and growth [240-242]. Today, more than half of the world's population lives in urban areas $(73 \%$ of the population in Europe), and this share is expected to continue to increase [243]. While urban areas cover a relatively small fraction of terrestrial land (less than 3\%) [244], they are responsible for more than $60 \%$ of the energy consumption worldwide [245], [246]. Urban areas also embody the heaviest consumption of natural resources and production of pollution and waste: they are estimated to account for over $70 \%$ of the total GHG emissions associated with anthropogenic activities, which are recognized as the main driver of global warming [243], [247]. A relevant reduction of the resource requirements and emissions associated with urban areas would be a major contribution at local and global scales [243], [247-249].

In the last decades, the emerging concept of sustainable development has led to a generally wide interest on identifying an environmentally sustainable urban form (i.e. the spatial configuration and shape of a city), as it has been recognized to strongly affect environmental performance in the built environment [249-252]. Attention has been paid to the debate on the effects of two archetypal concepts: the compact and the disperse city. However, the complexity of the multi-dimensional linkages between urban form and environmental impacts associated with human activities makes it challenging to achieve consensual agreement, or universally applicable solutions [249], [252]. While some urban planning and design principles are generally supported to improve environmental performance, such as compact, dense and mixed use developments, sustainable transportation systems and green infrastructure, there is an evident need for empirical frameworks to assess and to compare alternative approaches, strategies and policies, to inform planners, designers and decisionmakers [249], [251], [252]. 
Buildings are one of the most significant contributors to resource use and environmental impacts in urban areas [253]. Most research has focused on individual buildings and building components or materials, and environmental assessments have addressed in-dwelling resource, energy requirements, and associated environmental impacts [254-257]. Several studies have explored the influence of urban form and design characteristics on the environmental performance of buildings [255], [258], [259], in particular comparing different building typologies, such as apartment buildings and single family housing (e.g. [260], [261]). However, buildings affect anthropogenic activities and demands well beyond in-dwelling requirements. As an example, location, design and density in the built environment influence mobility choices, including active travel [5], [262], [263], [264]. The interplays between buildings and the urban scale should be addressed, in order to adequately assess and evaluate different planning strategies and policies.

Research on low-energy buildings has explored the potential for architectural design and building systems to satisfy their users' energy needs, or even to generate more energy than they require [265]. For instance, district energy systems (e.g. heating, cooling and domestic hot water supply in a neighbourhood, a city centre, or a city) can play an important role in urban sustainability, as they can have lower environmental impacts, when compared with conventional systems [266]. Nowadays, the main challenge of fossil fuel based district energy systems is to replace them by renewable energy based systems (e.g. solar energy, biomass, geothermal, and seasonal heat storage). The use of alternative energy technologies (e.g. heat pumps and polygeneration [266]) is also challenging. Therefore, centralized energy systems face as future challenges the supply of district heating (or cooling) in a scenario of new low-energy buildings; the reduction of the network energy losses in the distribution grid; the integration of renewable energy sources; the reduction of energy waste; the encouragement of integrated and smart management of electricity, gas, fluids and thermal grids; and the assurance of suitable planning and cost structures to transform the energy systems into more sustainable systems [267].

Another crucial link between urban form and environmental performance is on the connection between land use and transportation impacts. Many empirical studies have provided insight on how the distribution of activities (e.g. residential, employment, education, leisure and shopping) and infrastructure (e.g. energy, transport) in urban areas might affect relative performance of private transportation and transit systems and, consequently, users' mobility demand and choices [268-274]. 
In addition to the resource consumption and the regional and global environmental impacts, transportation plays a central role in urban sustainability due to its dominant contribution to local ambient air pollution and consequent health effects [275], [276]. Urban form determines where transportation emissions occur (through infrastructure layout), the dispersion and resulting ambient concentration levels of pollutants (through the configuration of buildings and street canyons), and population exposure (through land use, density and the resulting population distribution). While denser mixed urban areas might contribute to less motorized transportation demand and promote active travel, they are often associated with higher exposure to traffic-related noise and air pollution [277].

The urban heat island, which has also been subject of research for decades [278], is particularly relevant as climate change contributes to an increasing occurrence of extreme climate events, which are intensified by heat island effects [279], [280]. The rise of the urban air and surface temperatures is associated with different urban form features, such as the type of land-cover and density patterns, the use of low albedo materials, impermeable surface areas, etc. [281]. Urban climates can be evaluated using thermal remote sensing [282]. These techniques allow the identification and characterization of urban hot spots [283-285], supporting decision-making on strategies to prevent or decrease the potential effects of heat waves, which have been often associated with higher mortality and morbidity [286]. Some of the mitigation strategies include creating and increasing vegetation areas, reducing impervious surfaces [287], [288]; designing buildings and urban pavements with high albedo and low absorptance materials; and improving urban form, including the geometry and orientation of buildings, in order to improve airflow, reduce heat effects and improve air quality [278].

Public outdoor lighting, which has increased up to $20 \%$ per year [289], also affects urban energy demand. Public lighting is needed for street and traffic lighting: it contributes to safety, potentially reducing accidents, injuries and crime rates, and increasing pedestrians comfort, thus motivating increased road and street use [290]. Outdoor public lighting can represent up to $3 \%$ of the electric energy consumption in a city [291]. Poor lamp design or maladjusted lighting may also result in "energy waste" and "light pollution" (e.g., higher energy consumption and sky glow) [289], [292]. The development of innovative lighting technologies (e.g. solid state lighting lamps [293-295]) and new strategies for the management of public lighting (e.g. dimming [296], [297]) is a challenging area of research, towards a more sustainable urban environment. Photovoltaic panels with battery storage 
allow having powered renewable energy stand-alone lighting, thus reducing GHG emissions associated with artificial lighting [298]. However, this kind of approach does not work at all times and there is a trend for increasing research on alternative renewable energy solutions for stand-alone applications (e.g., fuel cells) [299]. At the policy level, several cities have been implementing public lighting energy efficient measures, such as substituting bulbs of public lamps for more energy efficient alternatives, with expected direct energy savings that can return the investment in less than 5 years [300]. However, in the past, energy efficiency policies have produced the "rebound" effect of stimulating the overall use of artificial lighting [289]. More efforts have to be carried out to foster sustainable public lighting policies.

Most studies and current practice have focused on specific sectors and urban components, such as buildings or transportation, isolating them from the urban context and its implications, and addressing one or two environmental indicators (mostly energy and GHG emissions) [254], [255]. The literature includes few examples of holistic system approaches that provide an empirical understanding of how different urban form characteristics influence the global and local environmental impacts of cities; however, understanding and addressing these interplays between different components and the urban scale and addressing a wider set of environmental and health effects is crucial to identify and avoid unintended trade-offs in decision-making [248], [254], [255], [301], [302]. To better inform and support planners, designers, and decision-makers in general, there is a need to widen the scope of empirical assessments, with comprehensive approaches that can identify improvement opportunities, as well as potential trade-offs, to evaluate and compare strategies and policies that can reduce environmental impacts associated with urban areas.

Industrial ecology tools have been used to assess the environmental performance of the built environment, including urban metabolism, material flow analysis and LCA (e.g. [240], [303-306]). These tools have great potential in the assessment of urban systems because they can quantify resources used and potential environmental impacts associated with processes within and beyond the geographic limits of an urban area (e.g. raw materials extraction or energy production), with consistent metrics [307], [308]. A comprehensive and function-centered character can be particularly useful in comparing alternative strategies or designs and in identifying improvement opportunities and tradeoffs between a wide diversity of impact indicators [301]. These tools have been widely applied to buildings and building elements [256], [257], and to whole cities or metropolitan areas [301]. There is 
an increasing trend to apply them to intermediate urban scales, such as neighbourhoods, addressing the interplays between different components of urban systems (e.g. urban density, mobility demand, shared equipment and infrastructure, etc.) [309], [310].

\section{Influence of commuting in the urban economies and the environment}

Transport policy is a central issue in urban governance with critical impacts in terms of energy consumption. The decision to become a commuter is to a large extent dependent on transportation costs borne by households (both in monetary and in time spending). When local, regional or federal governments decide to build a new highway or a bridge, or to finance public transportation or to develop transport networks, in fact, they are using taxes to favour those that will use such infrastructures more intensively. On the contrary, when the burden falls on the commuter (at least in the long term) commuting is discouraged. Indeed, the recent decrease in international oil price, which could lead to important and sustained deflation in fuel prices, may reduce the costs supported by those that commute by car and contribute to increase commuting attractiveness. Accordingly, the argument runs that national governments should maintain the prices at a significant level. This can be done through fiscal policy on "oil and its derivatives" or through the introduction of subsidies that are in turn applied to improve the quality of life of those living in the central business district (CBD) [311]. These measures can be complemented by, for example, the introduction of congestion tolls (already applied, with different specifications, in London, Singapore, Durham or Milan). Alternatively, parking policies could be applied to reduce traffic in the city centre [312], [313] and give priority to benefit noncommuters living in the $\mathrm{CBD}$, in occupying the limited number of parking places available there. Without doubt, while roads and highways are built to reduce congestion, it seems that these infrastructures also contribute to exacerbate commuting and to increase GHG emissions.

The growth of megacities has been intrinsically linked with increasing sprawling that compels millions of workers to commute. Commuting has often been "either neglected or typically seen as the market working just fine" [314]. In a more "traditional" economic view, if commuting is seen as the cost of time and distance, then commuting is only an option if it is compensated by either a rewarding job or by additional welfare gained from a pleasant living environment. However, as a mass phenomenon, commuting has benefits and costs well beyond those supported by each individual, which further 
shape the economies and the environment. Indeed, it is indisputable that the growth of commuting has made a critical contribution for stretching urban areas' boundaries and exacerbating energy consumption and GHG emissions.

Taking into account the complexity of this phenomenon, to measure commuting impacts, an application of an innovative commuting satellite account (CSA) embodied in a multi regional inputoutput (MRIO) framework was proposed by Ferreira [315]. This tool is capable of simultaneously integrating five critical elements of commuting: (1) commuting flows are represented in a specific geographic and economic context [316]; (2) commuting influences the regional distribution of income [317]; (3) commuting affects household consumption structures; (4) commuting is intrinsically linked with the rental prices of housing and business premises [318]; and, (5) commuting is a major cause of energy consumption and $\mathrm{CO}_{2}$ emissions [319]. These dimensions are widely acknowledged in the literature but the design of a modelling framework capable of incorporating all of them within the context of a specific region is still missing from regional and urban economic studies. So, to assess commuting opportunity costs, the CSA extension to the MRIO framework has already been applied to the Lisbon Metropolitan Area (LMA) and the results are illustrative of what could be the social increase in well-being if somehow policy measures and urban planning were applied efficiently and properly. Two hypothetical extreme scenarios were considered for this, both assuming that commuters change their status to non-commuters: one by considering the change of their place of residence to the municipality where they work; and the other one by assuming that the corresponding production activities are displaced to the suburbs [320]. According to the results, in the case of a less sprawled city, important savings would emerge in terms of economic, social and environmental (opportunity) costs. In this scenario, where agglomeration forces are strengthened and density increases, the end of commuting flows and, consequently, a change in households' consumption structure, contributes to an expansion of the national economy. Therefore, for the LMA, the gross value added (GVA) loss in the suburbs (216 million Euros in the Península de Setúbal and 43 million Euros in the "Rest of the Country") is more than offset by an increase in Greater Lisbon GVA (921 million Euros). The difference between the benefits in Greater Lisbon and the losses in Península de Setúbal and the "Rest of the Country" indicates that the Portuguese GVA would increase by $0.5 \%$. This is even more relevant as energy consumption and $\mathrm{CO}_{2}$ emissions should simultaneously decrease (about $0.7 \%$ of the national emissions). This is exclusively due to the reduction in the consumption of "oil and its 
derivatives" (which decreases more than 150000 toe), as the economy expansion would lead to an increase in the consumption of natural gas and coal (increasing approximately 33000 and 17000 toe, respectively).

On the other hand, if commuting vanishes due to the economic activity dispersion towards the suburbs, the economic consequences would be likely to be globally negative, despite the increase in the suburbs' economic production. Therefore, the Península de Setúbal and the "Rest of the Country" GVAs would increase by more than 4,159 and 883 million Euros, respectively. However, the decline in Greater Lisbon would be much more significant leading to a $1.5 \%$ loss in national GVA. In terms of employment, the national decrease would be less significant (approximately $0.5 \%$ ) as the economy would be more concentrated in less productive regions (and so, more workforce would be needed for the same amount of Output). Thus, for the LMA case study, the results indicate that the dispersion would imply a reduction in economic productivity that would overwhelm the benefits of ending commuting.

The comprehensive analysis of these first applications indicates dichotomous, yet complementary, conclusions: commuting, by itself, induces significant economic, social and environmental costs, although commuting, as one of the many elements associated with the agglomeration phenomenon, is undoubtedly linked to increasing productivity and economic growth. The "apparent neutrality" of commuting, promoted by some governmental and political institutions, has contributed to a situation where commuting prevails and will probably continue to be more and more relevant in the future [321]. Undoubtedly, a new perception of commuting can have a decisive role in supporting policy designed to accomplish the $11^{\text {st }}$ Sustainable Development Goal of the UN 2030 Agenda [322], which calls upon world leaders to make cities and all "human settlements inclusive, safe, resilient, and sustainable".

\section{The importance of consumer preferences on the diffusion of electric vehicles}

Road transportation has a negative impact on the environment through the release of harmful emissions and the high consumption of oil derivatives. Increasing the number of non-fuelled vehicles on light duty vehicle fleets, such EVs, has been pointed out as one of the solutions that may potentially 
decrease this environmental burden. This context led to the implementation of several measures worldwide in order to increase the circulation of EVs over fuelled vehicles. As a result, nearly all automotive manufacturers have at least one EV model on their fleets. From the policy-makers side, several governments designed and implemented policy packages to encourage consumers to purchase EVs, with purchase subsidies [323-326], taxes exemption [327-331] or the allowance of drive in low occupancy lanes being the most commonly applied policies [326], [328], [332-334]. However, the market penetration of EVs depends on the DR. As consumer preferences are considered one of the most important factors that influence the decision of purchasing a product [335], a satisfactory match between vehicle characteristics and consumer preferences is crucial for gaining market acceptance of these products [336] and it is vital in the development of such new products and policies design [337]. Preference information for EVs is also particularly important to support companies in adjusting their new vehicles characteristics according to consumer evaluations and requirements for future vehicle adoption [338], [339]. The extensive number of studies focused on consumer preference analysis for EVs underlines the importance of considering such information to effectively increase the market penetration of these vehicles. The analysis of the time horizon of those studies highlights the current relevance of understanding the consumer concerns on the diffusion of EVs with more than $60 \%$ of the 100 studies reviewed being developed from 2000 onwards.

In the literature, two main research lines are identified. One line comprises studies focused on the consumer preferences assessment for EVs, where two main trends and gaps were identified. The first trend regards the geographical scope of the studies. In the 80 s and 90 s, North American markets were the focus of most of the studies (e.g. [340-344]), a trend that shifted to European (e.g. [345-349] and Asian markets since 2000 (e.g. [350-353]). There are, however, several countries that have strongly encouraged electric mobility, for instance by joining the EVs Initiative [354], that remain to be analyzed. Therefore, focusing the analysis on such countries is suggested for future studies, namely France, Portugal, Sweden, Italy and Spain. The second trend regards the methodology used to estimate the consumer preferences, with all the studies using Discrete Choice or Conjoint Analysis models as estimation procedures. Considering the diversity of methodologies that can be used to estimate and analyze consumer preferences it is suggested the preference analysis using other methodologies, for instance through the Analytic Hierarchy Process method or the Multiattribute Utility Theory method. 
The other line of research concerns the analysis of influential factors on consumer preferences for EVs. The main influential factors were gathered in three main groups: technology, consumer and context. Purchase cost, battery limitation and charging time were the main technology-related factors analyzed. Regarding the consumer-related factors, five characteristics are the most focused in the literature, namely age, gender, income, level of education and family size. The context-related factors commonly involve the analysis of the influence of the fuel price, the development of charging infrastructure, social exposure and government policies on EVs diffusion. In these studies, the influence of some factors is corroborated in all studies, such as the "positive" influence of fuel price increments (e.g. [324], [332], [355]) and the "positive" influence of the charging infrastructure on increasing the demand of EVs (e.g. [329], [356-360]). However, the influence of other factors was not easily identified so far, namely the influence of consumer factors, such age and income, or the influence of some government policies, such as purchase and tax incentives. Therefore, future studies should address the analysis of these factors in order to achieve robust conclusions regarding their influence on EVs diffusion. A trend identified in the second line of research is the overall assumption that consumer preferences are static. As several researchers analysed the consumer preferences for EVs and concluded that they were dynamic, [361-364], i.e. preferences are likely to change under different market conditions, ignoring or underestimating the evolution of preferences may lead to inaccurate predictions of vehicle market shares [347], [363]. In this context, dynamic preferences should not be left out from new vehicle technologies analysis [362]. It is then suggested that dynamic preferences on EVs diffusion studies should be considered as a research direction to address in future studies.

\section{Factors influencing the environmental impacts of electric vehicle adoption}

EVs have the potential to drive the transport sector towards sustainability by reducing GHG emissions, fossil fuel dependence, and urban pollution. However, a large-scale adoption of EVs faces significant challenges and its environmental merits depend on a number of direct and indirect factors, which should be assessed considering a LC perspective [365-368]. The LCA methodology [369], which takes into account the impacts arising from vehicle manufacturing, use and end-of-life, as well as 
potential indirect effects in other systems, has been widely applied, uncovering environmental hotspots and trade-offs of EV adoption.

The electricity source used for charging has been pointed out as one of the most critical factors in the environmental assessment of EVs and in the comparison with conventional technologies [365], [370-373]. Only if EVs are charged with low fossil-content electricity can their adoption lead to high GHG reductions [365], [370], [373-375]. However, the assessment of emissions from EVs charging is complex and can be performed using different perspectives [376]. On one hand, EVs electricity consumption can be regarded as part of the total load of the electricity system (attributional approach); therefore, average emission factors for electricity supply are employed. On the other hand, EVs can be considered a new load added on top of existing load (consequential approach) and marginal electricity supply and corresponding emissions should thus be used to assess the change induced in the electricity system due to EVs charging. Marginal effects can have a distinct and larger magnitude than the average behaviour of the electricity system, leading to very distinct results [377].

Irrespective of the approach taken, which depends on the research question leading the analysis, both temporal and geographical aspects underlying electricity generation should be considered. Because the electricity system varies significantly from country to country and even between regions, as regards energy sources, and technologies, driving the same EV in different geographical areas can result in very different environmental profiles [378-381]. Furthermore, the annual electricity mix can vary significantly from year to year, for instance, due to changes in electricity demand, technology portfolio, availability of renewables, and net imports [382]. Most importantly, it can vary significantly throughout the day resulting in different environmental impacts depending on the charging schedule [381], [383]. The time of EV charging and its effects on environmental impacts is a current topic of research [381], [383], [384], but there is still controversy regarding the optimal charging schedule [376].

A large-scale adoption of EVs entails changes in electricity demand potentially affecting the electricity system operation and configuration in the long term. On one hand, a shift towards electricity in the transportation sector will place an additional stress upon the electricity generation system and distribution infrastructure [385], [386]. On the other hand, EVs are also seen as a way of increasing renewable energy penetration, due to their potential demand response abilities [57], [385], [387]. 
Several studies have assessed the effects of EVs in the electricity system, regarding, for instance, the impact on energy and $\mathrm{CO}_{2}$ emissions [388-390], and the integration of renewable energy sources [385], [387]. However, few studies have addressed interactions between EVs and other potentially competing technologies in the grid, such as the interaction between large storage capacity (e.g., pumped hydro storage) and EV charging [391].

Factors influencing electricity consumption and therefore the environmental impacts of EVs include the driving profile, which should be assessed using real-world data [371], [381], [383], and temperature, which has an important effect on vehicle efficiency due to heating, ventilation, and air conditioning use, as well as temperature-related battery efficiency effects [392-394]. Regarding vehicle manufacturing, several authors have shown that vehicle and battery manufacturing impacts of EVs can be twice as those from conventional technologies (e.g., GHG emissions) [370], [374], [395] and a substantial body of literature has focused on the assessment of the environmental impacts of different battery chemistries for electric mobility using LCA [396-402]. Energy demand during battery manufacture is a source of uncertainty in LCA of batteries and can have higher influence in the results than battery chemistry [403]. Charge-discharge efficiency, cycle life and energy density are found to be equally relevant for the environmental impact of batteries [403]. Explicit consideration of these parameters, which are seldom considered in LCA studies, would increase robustness of results.

Resource depletion and toxicity impacts are major environmental concerns regarding battery manufacturing and disposal. Resource criticality issues, which arise from the use in batteries and electronic components of lithium and other scarce metals with limited global supply, have been pointed out as important factors to consider [404]. A large-scale adoption of EVs will potentially affect reserves of these minerals, and extensive and efficient recycling systems, which are currently poorly developed, will be needed [405]. Other authors have focused on the reuse of EV batteries for stationary storage as a way of minimizing LC impacts [406-409], but have not analyzed the effect of delaying scrapping in future resource availability. Toxicity impacts resulting from mining processes associated with the production of electric powertrain components are also an area of concern [370], [374]. However, there is a lack of robust LC impact assessment methods for both toxicity and resource depletion, and these impact categories are usually disregarded in LCA studies of EVs, leading to an underestimation of important environmental burdens [370]. 
The impact reduction potential of EVs is also dependent on the environmental performance of the displaced technology [404]. EVs environmental benefits will depend on how they compare with increasingly more energy-efficient conventional vehicles, as the introduction of EVs in the fleet is gradual and its effects will not be seen in the short term [410]. Therefore, the assessment of the environmental impacts of EVs adoption should consider dynamic aspects regarding the shift of technologies over time, as well as advances in material processing, technology development and changes in electricity production [373], [411]. Applying a dynamic fleet-based LC approach, as opposed to a single-vehicle LCA, can help capture these effects as well as the scale and timing of changes, so that indirect impacts on other systems (e.g., the electricity system) can be assessed [412]. Potential environmental rebound effects arising from the different cost of electric and conventional vehicles and the different operation conditions of these technologies (e.g., range, refueling/re-charging convenience, which may divert some of the vehicle kilometres travelled to alternative transportation modes) should also be taken into account in LCA studies to inform policy making [413].

\section{Challenges of emerging biofuel technologies}

Sustainability is presently an essential principle in environmental resources management [414], [415]. Currently, it is increasingly clearer to society that the continued use of fossil fuels for energy purposes is unsustainable. Increasing difficulties and costs in exploration of oil global reserves, and the need to reduce GHG emissions associated with their use worldwide are undermining the usage of fossil fuels. In this context, biofuels are particularly important since they can be used in today means of transportation with little or no engine modifications. Additionally, it could present an important option for means of transportation that lack other fuel options, especially trucks, ships and aircrafts.

First generation biofuels derived from terrestrial crops such as sugarcane, soybeans, maize, rapeseed, among others, inflict a lot of pressure on the global food markets, contribute to water scarcity and precipitate the destruction of forests [416]. Therefore, other innovative technologies and sources of energy must be developed to replace fossil fuels. The overall sustainability of biofuels will depend on the development of viable, sustainable, advanced technologies that do not appear to be commercially viable yet. In this perspective, various feedstocks for producing advanced biofuels are 
generating substantial awareness in many countries for their advantages in relation to first generation biofuels. Several studies have been conducted on the technical feasibility of growing different types of organisms for biofuel production in the laboratory [417-420], which have proved the absence of many of the major drawbacks associated with current biofuels. However, although several companies are emerging in this developing area, the price of these biofuels still appears to be too high to be competitive when compared to currently used fuels, even renewable ones. Therefore, economic feasibility is believed to be currently the main hurdle to overcome for still immature biofuel technologies. On the other hand, the price of oil, their main competitor, is considerably low (US $\$ 44.23$ per WTI crude oil barrel in July 10th, 2017) [421].

In order to boost the adoption and development of advanced biofuels, there is a strong need to influence both the speed and the direction of the innovation and technological change. With that in mind, policymakers are putting their efforts to support the development of emerging renewable biofuels, either through direct means such as government-sponsored research and development (R\&D), or by enacting policies that support the production of renewable technologies [422].

The question is not whether advanced biofuels are technically possible, but rather focuses on the issue of whether they can be produced in a sustainable (environmental, economic, and social) manner and at a scale sufficient to help contributing to the world's fuel demand. Advanced biofuels have, consequently, a strong potential in multiple domains, such as energy, food and agriculture, national supply security and sustainability. The task that remains is how to disentangle the puzzle of a sustainable production process. It will, thus, require innovative dimensions of political and institutional cooperation to achieve the solution to this complex challenge.

\section{Sustainability of bioenergy systems}

Bioenergy production involves a chain of activities, from the growing of feedstock to energy conversion and use, which encompasses several sustainability challenges. GHG emissions of bioenergy systems have been the focus of many research studies [423], [424], and recently other relevant environmental impacts have been assessed, including those deriving from Land-Use Change (LUC) [425-427], and the impacts on biodiversity, water resources, water, air and soil quality [428-430]. In addition, it is of 
importance to consider social-economic impacts of bioenergy together with environmental impacts when assessing sustainability of bioenergy production [431].

Environmental impacts of bioenergy are different in the various phases of its chain, but also depend on the pathway namely on factors such as feedstock characteristics, production location, agricultural practices or the conversion efficiency of biomass. The growing demand for land for biomass production results in the conversion of land to agricultural use and/or improvement of productivity on existing farmland, thus causing direct and/or indirect LUC [432]. LUC is an important driver of increased GHG emissions and may lead to altered soil organic carbon [433-435] and changes in a host of ecosystem services [436]. In addition, LUC is regarded as one of the major drivers of the ongoing loss of biodiversity [437]. Besides LUC, water impacts of biomass production have been receiving growing attention from researchers and are typically distinguished in terms of water availability, due to irrigation or divert water used to grow food crops, and water quality impacts [430]: nitrogen or phosphorous fertilizers and pesticides used in crops cultivation can enter in water and soil causing impacts such as eutrophication (algal growth), aquatic oxygen depletion, toxicity and loss of biodiversity. Although most renewable energy technologies have lower impacts than conventional ones, electricity generation from biomass can produce significant NOx, particulate matter (PM), and hazardous air pollutants, such as polycyclic aromatic hydrocarbons (PAHs) [438]. In addition, Malça et al. [439] showed that emissions of PM are significantly higher when biodiesel is used in pre-Euro heavy-duty vehicles (up to double the emissions of fossil diesel use), with direct implications on air quality and potential health problems.

Social-economic impacts of bioenergy identified in existing literature include both positive and negative impacts. Negative social-economic impacts of bioenergy found in previous studies are associated with food security, land tenure and labour rights. According to a World Bank study [440], bioenergy production will push up prices for food staples, causing $3 \%$ price rise of corn and other major grains, and $8 \%$ of sugar by 2020 . Increasing food prices are expected to have larger negative impacts on people from developing countries, who spend a greater share of their income on food. A number of developing countries have observed increasing conversion rate of food-to-energy land use in order to meet the increasing demand of biomass from developed countries. Competition for land between food and energy may lead to conflicts of land tenure [441-443]. Field workers of bioenergy croplands in developing countries have been reported to suffer from poor working conditions from 
excessive working hours to lack of assurance of occupational health and safety [444]. Respiratory diseases of workers and local communities due to particulate matter emissions are among the negative social impacts of bioenergy production and use [445]. Positive social-economic impacts of bioenergy are related with its contributions on economic development and job creation. Bioenergy production can contribute to the income of agro-business and create job opportunities cost-effectively [446], [447]. Investment cost of creating one job in bioenergy industry is estimated to be lower than in fossil fuel and other renewables [448].

As indicated by the impacts identified above, environmental and social-economic impacts of bioenergy need to be assessed from a supply chain perspective, considering various stakeholders. LC methodologies such as LCA [449], Life-Cycle Costing (LCC) [450], Social Life-Cycle Assessment (SLCA) [451] and Life-Cycle Sustainability Assessment (LCSA) [452] have the abilities to assess impacts associated with a supply chain. LCA aims at assessing the environmental impacts of a product (or service) throughout its LC, and its methodologies are well established with two international standards ISO 14040 and ISO 14044. LCA has been widely applied to assess environmental impacts of bioenergy systems [453]. LC approaches assessing social-economic impacts such as SLCA, LCC, and LCSA are relatively novel methods, and call for further methodological development and practices of case studies. However, bioenergy is among one of the most assessed topics in existing studies [454-456]. Although the depth and breadth of LC approaches have developed rapidly in the past decades, further research is needed to consolidate important controversies and close methodological gaps. In LCA, further development on impact assessment methods is crucial on the following issues [457]: a) characterization of impacts on biodiversity, land use change and water footprint; b) integration of spatial and temporal perspectives on regional impact categories (e.g. acidification, eutrophication and toxicity); and c) characterization of field emission to soil and water considering site-specific soil conditions. Consensus should be reached on the applicability of various types of LCA methods (e.g. attributional vs. consequential), and how to account for uncertainties when interpreting LCA results [458]. SLCA, LCC and LCSA all possess a short history of methodological developments, international standards and widely-accepted documentations still need to be established or updated.

To ensure sustainability of bioenergy systems and to maximize the benefits of using biomass as energy source while avoiding negative environmental and social-economic impacts, there is the 
need, in one hand, to increase the comprehensiveness and robustness of LC sustainability assessment tools by addressing the aforementioned limitations and integrating uncertainty analysis [458], [459] and, on the other hand, to develop policies that promote the development of technologies to efficiently convert feedstocks such as forestry or agricultural wastes [460]; to investigate alternative feedstocks to increase feedstock diversification; to improve agricultural management practices [461]; and to develop regional plans for bioenergy production taking into account the type of feedstocks available in the regions. Moreover, due to the different criteria that need to be taken into account to support the development of sustainable bioenergy systems and policies there is a research need to provide tools that support the interpretation and communication of LC results considering trade-offs among the different dimensions of sustainability in a scientifically sound manner. A potential approach that has been gaining prominence is to use Multi-Criteria Decision Analysis (MCDA) [462] as it provides a structured decision support framework that can be used to integrate the LC data in the form of easily understandable rankings, performance scores, and classifications of the systems and policies under evaluation [460].

\section{Conclusions}

This paper presented and discussed several topics on energy systems towards a more sustainable and energy efficient future. The multidisciplinarity of the covered issues reflects the character of both the EfS Initiative of the University of Coimbra and the Sustainable Energy Systems focus area of the MIT-Portugal Doctoral Program. On the other hand, the diversity of the subjects discussed in this paper emphasizes the importance of analysing different energy systems and their interrelations in a more holistic way. The next paragraphs outline the main conclusions of the paper, highlighting some areas of research that should be further investigated in the near future.

- A paradigm shift is faced in the electricity system. Pursuing a more sustainable electricity system is driving all stakeholders, imprinting the increasing need for reliable renewable technologies. Moreover, electricity system reforms in Europe are aiming for unified and competitive electricity markets. The increasing penetration of renewables and the pressure on GHG emissions are in everyone's mind. Stakeholders promote the discussion of the impacts of this shift and try to 
prepare for the change that is already happening. The need to research the different impacts of renewables on electricity markets, a vast field of study, was never so important.

- The transition of the electricity sector toward a smarter and more sustainable setting brings challenges for DSOs and their role in a changing sector. These challenges encompass complex institutional, technological, and organisational issues, associated with their roles, activities, and responsibilities. In this context, while technological and institutional aspects have received significant attention, the organisational dimension has been explored to a lesser extent. However, a transition in technologies and policies that is not matched by a more detailed understanding of the organisational behaviour of DSOs can hinder innovation in the sector and halt the delivery of benefits to connected consumers. Given this, research efforts that explore the organisational characteristics of electricity distribution companies, as a source of insight on flexibility and adaptability of the electricity distribution industry, can be valuable for the design of new policies and business models for DSOs.

- DR remains an interesting research topic because it must consider the uncertainty associated to consumer and utility adoption as well as the randomness of loads use, the intermittency of renewables generation and energy storage. The increased study of DR may certainly help to verify and justify possible investments in its enabling technologies.

- CRE initiatives are relatively new stakeholders in energy systems and energy markets, and they are important actors in the energy transition in a number of countries in Europe. The literature has observed major differences in the diffusion of the CRE model among European countries, and has identified systemic factors, drivers and barriers for the development of such enterprises in countries where the CRE model is well established. Using these examples as a point of departure, it would be fruitful to conduct similar case studies to analyse the development of CRE in the South and East of Europe, where the sector is emerging at a much slower rate as compared to the north and west of the continent, and draw comparisons. Biophysical conditions in Southern and Eastern Europe for distributed energy systems are unquestionable, especially in the south of the continent with its abundance of solar radiation. Therefore, such analysis may indicate systemic factors (technical, institutional, cultural) intrinsic to those countries landscapes that are hindering similar results of CRE initiatives. In order to obtain the required data, it is 
necessary to undertake "desk and field" research, surveys and interviews with CRE initiative members in Southern and Eastern Europe. The results will help CRE initiatives to align their development strategies with the prevailing environments and stages of energy transitions in their local landscapes, and can provide guidance for policy makers. Such a multiple case-study would evaluate the transferability of existing CRE models to countries where citizens are not active in the field of renewables, or where their deployment is progressing at an unsatisfactory rate. It would also improve the understanding of "if" and "how" CRE initiatives can provide bottom-up contributions to those countries efforts for achieving short and long term renewable electricity generation targets (EU 2020, 2030, 2050).

- The IO-MOLP models are practical and useful as an analytical tool for empirical research supporting the policy making in a wide variety of problems. This combination of MOLP with IO methods plays a supplementary role in understanding the interactions between the economic and energy systems, and the corresponding impacts on the environment, offering a consistent framework for assessing the effects of distinct policies. The possibility of extending and integrating the IO-MOLP model with other methods in order to assess the interactions between the economic activities, energy requirements and the environment is particularly appealing. The integration of IO-MOLP model with hybrid formulation and LCA approaches allows incorporating different processes into the model and expanding the boundaries of analysis and can be applied for specific energy commodities. In addition, inter-regional IO-MOLP models could be useful for the analysis of e3 policies for specific regions/states, whereas coupling the treatment of uncertainty could provide more robust outcomes.

- Urban form directly or indirectly influences most environmental impacts associated with urban areas, from local water and air quality, to GHG emissions and global climate change. Most research has focused on specific sectors and urban components, such as buildings or transportation, isolating them from the urban context and its implications, and addressing one or two environmental indicators (mostly energy and GHG emissions). However, it is important that urban components (such as buildings and transportation systems) are addressed together, with a comprehensive approach centered on users, and considering a wide range of environmental and health impacts, in order to identify and avoid unintended trade-offs in decision-making. Industrial ecology tools can be applied in the development of such holistic approaches. The empirical 
understanding of the linkages between urban form and environmental performance is crucial to enable the potential of urban planning and design in reducing environmental impacts associated with anthropogenic activities, which is especially relevant due to its comprehensive and long lasting effects.

- Future research concerning commuting impacts needs to be performed taking into account the local and regional specificities of each geographical space. This can help to uncover the most adequate policies to reduce commuting and its environmental impacts. The solution is not independent from the cultural, economic and social backgrounds of a given region. What is clear is that urban and regional planning matters and they should be made at the correct level of governance. Finally, land-use and transport policy can favor less sprawled regions and, consequently, less commuting with significant impacts in the energy consumed and in the GHG emissions.

- The analysis of consumer preferences for EVs is a very active research field in transportation studies. Future research should continue to address the preference analysis as it will allow to efficiently achieve the market penetration targets defined for EVs in each considered market.

- The environmental impacts of EVs adoption result from the intrinsic characteristics of the vehicles, but also from indirect factors arising from the interaction with the existing system. Research should focus, on one hand, on developing efficient recycling systems for batteries and maximizing its cycle life and charge-discharge efficiency, as well as, in assessing and minimizing toxicity and resource depletion impacts from battery manufacturing and other electric powertrain components. On the other hand, the interactions between EVs charging and the electricity system should also deserve further research, namely regarding the effects of EVs in power systems that also have utility-scale storage resources. Environmental impacts of EV adoption are affected by both spatially and temporally heterogeneous factors (e.g., climate, electricity mix, driving profiles) so that detailed analysis is needed for any specific energy and transportation system while considering future technological improvements. Potential environmental rebound effects of EVs adoption should also be taken into account when informing policymaking.

- Biofuels are particularly important since they can be used in means of transportation that need other fuel options, especially trucks, ships and aircrafts. However, produce advanced biofuels that 
are sustainable (economic, social and environmental) can be a difficult hurdle to surpass. This is even more challenging due to enduring low worldwide oil prices, the main biofuels competitor.

- The development and implementation of sustainable bioenergy systems involves a comprehensive assessment of their environmental and social-economic impacts from a supply chain perspective. LC approaches are promising tools to measure impacts in the required holistic manner but there is a need for further methodological development and to increase the comprehensiveness and robustness of LC tools by integrating uncertainty analysis. Moreover, there is very little research that has focused on how to measure trade-offs among the different dimensions of sustainability in a scientifically sound manner. The use of MCDA to integrate the LC impacts and to provide a structured decision support framework is an important issue for future research and for the sustainable development of bioenergy systems.

\section{Acknowledgment}

This work has been framed under the EfS Initiative of the University of Coimbra and the Sustainable Energy Systems focus area of the MIT-Portugal Program. It was partially supported by the Portuguese Foundation for Science and Technology (FCT) under grants SFRH/BD/52309/2013, $\mathrm{PD} / \mathrm{BD} / 105841 / 2014, \mathrm{PD} / \mathrm{BD} / 105991 / 2014$ (awarded in the framework of the MIT Portugal Program funded through the POPH/FSE), SFRH/BPD/99668/2014 and SFRH/BPD/114869/2016. The work has also been funded by FEDER funds through the COMPETE 2020-POCI, and by FCT in the framework of the projects POCI-01-0145-FEDER-016750 | PTDC/EMS-ENE/6079/2014, PTDC/EMSENE/3238/2014 | POCI-01-0145-FEDER-016760 | LISBOA-01-0145-FEDER-016760, POCI-01-0145FEDER-016764 | PTDC/AGR-FOR/1510/2014 and POCI-01-0145-FEDER-016765 | PTDC/AAG$M A A / 6234 / 2014$. Additionally, this work has been partially supported by FCT under project grant: UID/MULTI/00308/2013, and SAICTPAC/0004/2015-POCI-01-0145-FEDER-016434.

\section{References}

[1] N. Soares, L. Dias Pereira, J.-P. Ferreira, P. Conceição, and P. Pereira da Silva, "Energy efficiency of higher education buildings: a case study," International Journal of Sustainability in Higher Education, vol. 16, no. 5, pp. 669-691, 2015.

[2] H. Bernardo, A. Martins, and A. Gaspar, "The role of building automation and commissioning in energy efficiency of existing buildings: a research approach based on energy management and control systems enhancement," in Proc. 11th REHVA World Congress \& 8thInt. Conf. on Indoor Air Quality, Ventilation and Energy Conservation in Buildings, CLIMA 2013, 2013. 
[3] M. K. Votteler and A. G. Martins, "A sustainable development management system for the University of Coimbra," in Integrating Sustainability Thinking in Science and Engineering Curricula. Springer International Publishing, 2015, pp. 361-373.

[4] S. A. Batterman, A. G. Martins, C. H. Antunes, F. Freire, and M. Gameiro, "Development and application of competencies for graduate programs in energy and sustainability," Journal of Professional Issues in Engineering Education \& Practice, vol. 137, no. 4, pp. 198-207, 2011.

[5] N. Soares et al., "A review on current advances in the energy and environmental performance of buildings towards a more sustainable built environment," Renewable and Sustainable Energy Reviews, vol. 77, pp. 845-860, Sep. 2017.

[6] REN21, “Renewables 2016,” REN21, 2016.

[7] N. C. Figueiredo and P. P. Silva, "Explanatory variables on south-west spot electricity markets integration," in Assessment methodologies: energy, mobility and other real world application, P. Godinho and J. Dias, Eds. Imprensa da Universidade de Coimbra, 2015, pp. 65-88.

[8] A. Henriot and J. M. Glachant, "Melting-pots and salad bowls: The current debate on electricity market design for integration of intermittent RES," Utilities Policy, vol. 27, pp. 57-64, 2013.

[9] N. C. Figueiredo and P. P. Silva, "Renewables Optimization in Energy-Only Markets," in Analysis of Energy Systems. Management, Planning and Policy, V. Blanco, Ed. Taylor \& Francis, 2016.

[10] N. C. Figueiredo, P. P. Silva, and P. A. Cerqueira, "Evaluating the market splitting determinants: evidence from the Iberian spot electricity prices," Energy Policy, vol. 85, pp. 218 234, Oct. 2015.

[11] N. C. Figueiredo, P. P. Silva, and P. A. Cerqueira, "It is windy in Denmark: Does market integration suffer?," Energy, vol. 115, pp. 1385-1399, Nov. 2016.

[12] N. C. Figueiredo, P. Pereira da Silva, and P. Cerqueira, "Wind generation influence on market splitting: The Iberian spot electricity market," in 2015 12th International Conference on the European Energy Market (EEM), 2015, pp. 1-5.

[13] D. Newbery, "Missing money and missing markets: reliability, capacity auctions and interconnectors," Energy Policy, vol. 94, pp. 401-410, 2016.

[14] M. Boillot, Advanced Smart Grids for Distribution System Operators: Volume 1, vol. 1. Hoboken, NJ, USA: John Wiley \& Sons, Inc., 2014.

[15] I. J. Pérez-Arriaga, Regulation of the Power Sector, vol. 61. London: Springer London, 2013.

[16] M. Aiello and G. Pagani, "How energy distribution will change: An ICT perspective," in Smart Grids from a Global Perspective, A. Beaulieu, J. Wilde, and J. Scherpen, Eds. Groningen: Springer, 2016, pp. 11-26.

[17] C. Gellings, The Smart Grid: Enabling Energy Efficiency and Demand Response. Lilburn, GA: The Fairmont Press, Inc., 2009.

[18] E. Feess, J. Huber, J. Hemmelskamp, and M. Lehmann-Waffenschmidt, Sustainability Innovations in the Electricity Sector. Heidelberg: Physica-Verlag HD, 2012.

[19] European Commission, "Energy 2020. A strategy for competitive, sustainable and secure energy," Brussels, 2010. 
[20] European Commission, "A policy framework for climate and energy in the period from 2020 to 2030," Brussels, 2014.

[21] European Commission, "Energy Roadmap 2050," Brussels, 2011.

[22] European Commission, "A framework strategy for a resilient energy union with a forwardlooking climate change policy," Brussels, 2015.

[23] European Commission, "Clean Energy For All Europeans," Brussels, 2016.

[24] European Commission, "Directive of the European Parliament and of the Council on common rules for the internal market in electricity," 2017.

[25] European Commission, "Regulation of the European Parliament and of the Council establishing a European Union Agency for the Cooperation of Energy Regulators (recast)," 2017.

[26] European Commission, "Regulation of the European Parliament and of the Council on the internal market for electricity," 2017.

[27] P. Mallet, P.-O. Granström, P. Hallberg, G. Lorenz, and P. Mandatova, "European Perspectives on the Future of Electric Distribution," IEEE Power and Energy Magazine, pp. 51-64, 2014.

[28] European Union, "Directive 96/92/EC of The European Parliament and of the Council of 19 December 1996 concerning common rules for the internal market in electricity," 1996.

[29] European Union, DIRECTIVE 2003/54/EC OF THE EUROPEAN PARLIAMENT AND OF THE COUNCIL of 26 June 2003 concerning common rules for the internal market in electricity and repealing Directive 96/92/EC THE. 2003.

[30] European Union, "Directive of 2009/72/EC of the European Parliament and of the Council of 13 July 2009 Concerning Common Rules for the Internal Market in Electricity and Repealing Directive 2003/54/EC," Official Journal of the European Union. p. L 211/55 - L 211/93, 2009.

[31] E. Martinot, L. Kristov, and J. D. Erickson, "Distribution System Planning and Innovation for Distributed Energy Futures," Current Sustainable/Renewable Energy Reports, vol. 2, no. 2, pp. 47-54, Jun. 2015.

[32] P. Oosterkamp et al., "The role of DSOs in a Smart Grid environment," Amsterdam, 2014.

[33] CEER, "The Future Role of DSOs. A CEER Public Consultation Paper," Brussels, 2014.

[34] CEER, "The Future Role of DSOs. A CEER Conclusions Paper," 2015.

[35] J. Markard, R. Raven, and B. Truffer, "Sustainability transitions: An emerging field of research and its prospects," Research Policy, vol. 41, no. 6, pp. 955-967, 2012.

[36] B. Praetorius et al., Innovation for Sustainable Electricity Systems Exploring the Dynamics of Energy Transitions. Heidelberg: Physica-Verlag, 2009.

[37] A. Purvins, I. T. Papaioannou, and L. Debarberis, "Application of battery-based storage systems in household-demand smoothening in electricity-distribution grids," Energy Conversion and Management, vol. 65, pp. 272-284, Jan. 2013.

[38] A. J. Guwy, S. Carr, R. M. Dinsdale, J. Maddy, and G. C. Premier, "Energy storage for active network management on electricity distribution networks with wind power," IET Renewable Power Generation, vol. 8, no. 3, pp. 249-259, Apr. 2014. 
[39] H. Zhao, Q. Wu, S. Hu, H. Xu, and C. N. Rasmussen, "Review of energy storage system for wind power integration support,” Applied Energy, vol. 137, pp. 545-553, Jan. 2015.

[40] M. Yekini Suberu, M. Wazir Mustafa, and N. Bashir, "Energy storage systems for renewable energy power sector integration and mitigation of intermittency," Renewable and Sustainable Energy Reviews, vol. 35, pp. 499-514, Jul. 2014.

[41] G. Carpinelli, G. Celli, S. Mocci, F. Mottola, F. Pilo, and D. Proto, "Optimal Integration of Distributed Energy Storage Devices in Smart Grids," IEEE Transactions on Smart Grid, vol. 4, no. 2, pp. 985-995, Jun. 2013.

[42] M. Huber, D. Dimkova, and T. Hamacher, "Integration of wind and solar power in Europe: Assessment of flexibility requirements," Energy, vol. 69, pp. 236-246, May 2014.

[43] T. Broeer, J. Fuller, F. Tuffner, D. Chassin, and N. Djilali, "Modeling framework and validation of a smart grid and demand response system for wind power integration," Applied Energy, vol. 113, pp. 199-207, Jan. 2014.

[44] R. Teixeira Pinto, P. Bauer, S. F. Rodrigues, E. J. Wiggelinkhuizen, J. Pierik, and B. Ferreira, "A novel distributed direct-voltage control strategy for grid integration of offshore wind energy systems through MTDC network," IEEE Transactions on Industrial Electronics, vol. 60, no. 6, pp. 2429-2441, Jun. 2013.

[45] R. R. Diaz, A. L. J. Alarcon, and R. J. Moreno, "Monitoring system for global solar radiation, temperature, current and power for a photovoltaic system interconnected with the electricity distribution network in Bogota," in 2013 IEEE 56th International Midwest Symposium on Circuits and Systems (MWSCAS), 2013, pp. 485-488.

[46] G. S. K, A. K. Rathore, A. Edpuganti, and D. Srinivasan, "Optimal low switching frequency pulse width modulation of current-fed five-level inverter for solar integration," 2016 IEEE Applied Power Electronics Conference and Exposition (APEC), pp. 943-950, Mar. 2016.

[47] L. Cheng, Y. Chang, and R. Huang, "Mitigating voltage problem in distribution system with distributed solar generation using electric vehicles," IEEE Transactions on Sustainable Energy, vol. 6, no. 4, pp. 1475-1484, 2015.

[48] J. Goop, M. Odenberger, and F. Johnsson, "Distributed solar and wind power? Impact on distribution losses," Energy, vol. 112, pp. 273-284, Oct. 2016.

[49] J. M. Foster, G. Trevino, M. Kuss, and M. C. Caramanis, "Plug-in electric vehicle and voltage support for distributed solar: Theory and application," IEEE Systems Journal, vol. 7, no. 4, pp. 881-888, Dec. 2013.

[50] X. Zhang, G. G. Karady, and S. T. Ariaratnam, "Optimal allocation of CHP-based distributed generation on urban energy distribution networks," IEEE Transactions on Sustainable Energy, vol. 5, pp. 246-253, Jan. 2014.

[51] A. Franco and M. Versace, "Optimum sizing and operational strategy of CHP plant for district heating based on the use of composite indicators," Energy, vol. 124, pp. 258-271, Apr. 2017.

[52] X. Ma, Y. Wang, and J. Qin, "Generic model of a community-based microgrid integrating wind turbines, photovoltaics and CHP generations," Applied Energy, vol. 112, pp. 1475-1482, Dec. 2013.

[53] A. Adam, E. S. Fraga, and D. J. L. Brett, "Options for residential building services design using fuel cell based micro-CHP and the potential for heat integration," Applied Energy, vol. 138, pp. 685-694, Jan. 2015. 
[54] M. Sorace, M. Gandiglio, and M. Santarelli, "Modeling and techno-economic analysis of the integration of a FC-based micro-CHP system for residential application with a heat pump," Energy, vol. 120, pp. 262-275, 2017.

[55] F. Ruzzenenti, M. Bravi, D. Tempesti, E. Salvatici, G. Manfrida, and R. Basosi, "Evaluation of the environmental sustainability of a micro CHP system fueled by low-temperature geothermal and solar energy," Energy Conversion and Management, vol. 78, pp. 611-616, Feb. 2014.

[56] J. E. P. Navalho, J. M. C. Pereira, and J. C. F. Pereira, "A methodology for thermal analysis of complex integrated systems: Application to a micro-CHP plant," Applied Thermal Engineering, vol. 112, pp. 1510-1522, Feb. 2017.

[57] D. B. Richardson, "Electric vehicles and the electric grid: A review of modeling approaches, Impacts, and renewable energy integration," Renewable and Sustainable Energy Reviews, vol. 19, pp. 247-254, Mar. 2013.

[58] R. C. Green, L. Wang, and M. Alam, "The impact of plug-in hybrid electric vehicles on distribution networks: A review and outlook," Renewable and Sustainable Energy Reviews, vol. 15, no. 1, pp. 544-553, Jan. 2011.

[59] M. D. Galus, M. Zima, and G. Andersson, "On integration of plug-in hybrid electric vehicles into existing power system structures," Energy Policy, vol. 38, no. 11, pp. 6736-6745, Nov. 2010.

[60] A. Zakariazadeh, S. Jadid, and P. Siano, "Multi-objective scheduling of electric vehicles in smart distribution system," Energy Conversion and Management, vol. 79, pp. 43-53, Mar. 2014.

[61] L. Schenato, G. Barchi, D. Macii, R. Arghandeh, K. Poolla, and A. Meier, "Bayesian linear state estimation using smart meters and PMUs measurements in distribution grids," in 2014 IEEE International Conference on Smart Grid Communications (SmartGridComm), 2014, pp. 572 577.

[62] M. E. H. Dyson, S. D. Borgeson, M. D. Tabone, and D. S. Callaway, "Using smart meter data to estimate demand response potential, with application to solar energy integration," Energy Policy, vol. 73, pp. 607-619, Oct. 2014.

[63] M. P. McHenry, "Technical and governance considerations for advanced metering infrastructure/smart meters: Technology, security, uncertainty, costs, benefits, and risks," Energy Policy, vol. 59, pp. 834-842, Aug. 2013.

[64] G. R. Barai, S. Krishnan, and B. Venkatesh, "Smart metering and functionalities of smart meters in smart grid - a review," in 2015 IEEE Electrical Power and Energy Conference (EPEC), 2015, pp. 138-145.

[65] R. Pereira, J. Figueiredo, R. Melicio, V. M. F. Mendes, J. Martins, and J. C. Quadrado, "Consumer energy management system with integration of smart meters," Energy Reports, vol. 1, pp. 22-29, Nov. 2015.

[66] S. S. S. R. Depuru, L. Wang, and V. Devabhaktuni, "Smart meters for power grid: Challenges, issues, advantages and status," Renewable and Sustainable Energy Reviews, vol. 15, no. 6, pp. 2736-2742, Aug. 2011.

[67] J. Aghaei and M.-I. Alizadeh, "Demand response in smart electricity grids equipped with renewable energy sources: A review," Renewable and Sustainable Energy Reviews, vol. 18, pp. 64-72, Feb. 2013. 
[68] T. Williams, D. Wang, C. Crawford, and N. Djilali, "Integrating renewable energy using a smart distribution system: Potential of self-regulating demand response," Renewable Energy, vol. 52, pp. 46-56, Apr. 2013.

[69] M. Mazidi, A. Zakariazadeh, S. Jadid, and P. Siano, "Integrated scheduling of renewable generation and demand response programs in a microgrid," Energy Conversion and Management, vol. 86, pp. 1118-1127, Oct. 2014.

[70] S. Maharjan, Q. Zhu, Y. Zhang, S. Gjessing, and T. Basar, "Dependable demand response management in the smart grid: A stackelberg game approach," IEEE Transactions on Smart Grid, vol. 4, no. 1, pp. 120-132, Mar. 2013.

[71] R. Deng, Z. Yang, M.-yuen Chow, and J. Chen, "A Survey on demand response in smart grids: mathematical models and approaches," IEEE Transactions on Industrial Informatics, vol. 11, no. 3, pp. 570-582, 2015.

[72] H. Kanchev, D. Lu, F. Colas, V. Lazarov, and B. Francois, "Energy management and operational planning of a microgrid with a PV-based active generator for smart grid applications," IEEE Transactions on Industrial Electronics, vol. 58, no. 10, pp. 4583-4592, Oct. 2011.

[73] A. Safdarian, M. Fotuhi-Firuzabad, and M. Lehtonen, "A distributed algorithm for managing residential demand response in smart grids," IEEE Transactions on Industrial Informatics, vol. 10, no. 4, pp. 2385-2393, Nov. 2014.

[74] U. C. Chukwu and S. M. Mahajan, "Real-time management of power systems with V2G facility for smart-grid applications," IEEE Transactions on Sustainable Energy, vol. 5, no. 2, pp. 558566, Apr. 2014.

[75] L. Hernandez et al., "A multi-agent system architecture for smart grid management and forecasting of energy demand in virtual power plants," IEEE Communications Magazine, vol. 51, no. 1, pp. 106-113, Jan. 2013.

[76] Z. Wang, B. Chen, J. Wang, M. M. Begovic, and C. Chen, "Coordinated Energy Management of Networked Microgrids in Distribution Systems," IEEE Transactions on Smart Grid, vol. 6, no. 1, pp. 45-53, Jan. 2015.

[77] H. Laaksonen, "Advanced islanding detection functionality for future electricity distribution networks," IEEE Transactions on Power Delivery, vol. 28, no. 4, pp. 2056-2064, 2013.

[78] E. Fadel et al., "A survey on wireless sensor networks for smart grid," Computer Communications, vol. 71, pp. 22-33, Nov. 2015.

[79] G. B. Giannakis, V. Kekatos, N. Gatsis, S.-J. Kim, H. Zhu, and B. F. Wollenberg, "Monitoring and optimization for power grids: A signal processing perspective," IEEE Signal Processing Magazine, vol. 30, no. 5, pp. 107-128, Sep. 2013.

[80] A. F. A. Aziz, S. N. Khalid, M. W. Mustafa, H. Shareef, and G. Aliyu, "Artificial intelligent meter development based on advanced metering infrastructure technology," Renewable and Sustainable Energy Reviews, vol. 27, pp. 191-197, Nov. 2013.

[81] E. S. Rigas, S. D. Ramchurn, and N. Bassiliades, "Managing electric vehicles in the smart grid using artificial intelligence: A survey," IEEE Transactions on Intelligent Transportation Systems, vol. 16, no. 4, pp. 1619-1635, Aug. 2015. 
[82] M. Q. Raza and A. Khosravi, "A review on artificial intelligence based load demand forecasting techniques for smart grid and buildings," Renewable and Sustainable Energy Reviews, vol. 50, pp. 1352-1372, Oct. 2015.

[83] W.-H. Chang et al., "Generating routing-driven power distribution networks with machinelearning technique," IEEE Transactions on Computer-Aided Design of Integrated Circuits and Systems, vol. 36, no. 8, pp. 1237-1250, 2017.

[84] R. Eskandarpour and A. Khodaei, "Machine learning based power grid outage prediction in response to extreme events," IEEE Transactions on Power Systems, vol. 32, no. 4, pp. 33153316, 2016.

[85] S. Ruester, S. Schwenen, C. Batlle, and I. Pérez-Arriaga, "From distribution networks to smart distribution systems: Rethinking the regulation of European electricity DSOs," Utilities Policy, vol. 31, pp. 229-237, Dec. 2014.

[86] L. Schiavo, M. Delfanti, E. Fumagalli, and V. Olivieri, "Changing the regulation for regulating the change: Innovation-driven regulatory developments for smart grids, smart metering and emobility in Italy," Energy Policy, vol. 57, pp. 506-517, Jun. 2013.

[87] P. M. Connor, P. E. Baker, D. Xenias, N. Balta-Ozkan, C. J. Axon, and L. Cipcigan, "Policy and regulation for smart grids in the United Kingdom," Renewable and Sustainable Energy Reviews, vol. 40, pp. 269-286, Dec. 2014.

[88] J. Crispim, J. Braz, R. Castro, and J. Esteves, "Smart Grids in the EU with smart regulation: Experiences from the UK, Italy and Portugal," Utilities Policy, vol. 31, pp. 85-93, Dec. 2014.

[89] P. Fox-Penner, Smart Power Anniversary Edition - Climate Change, the Smart Grid and the Future of Electric Utilities. Washington, DC: Island Press, 2014.

[90] J. Joode, J. C. Jansen, A. J. Welle, and M. J. J. Scheepers, "Increasing penetration of renewable and distributed electricity generation and the need for different network regulation," Energy Policy, vol. 37, no. 8, pp. 2907-2915, Aug. 2009.

[91] T. Jamasb and M. Pollitt, "Incentive regulation of electricity distribution networks: Lessons of experience from Britain," Energy Policy, vol. 35, no. 12, pp. 6163-6187, Dec. 2007.

[92] C. Cambini, A. Croce, and E. Fumagalli, "Output-based incentive regulation in electricity distribution: Evidence from Italy," Energy Economics, vol. 45, pp. 205-216, Sep. 2014.

[93] K. L. Anaya and M. G. Pollitt, "Integrating distributed generation: Regulation and trends in three leading countries," Energy Policy, vol. 85, pp. 475-486, Oct. 2015.

[94] V. Marques, N. Bento, and P. M. Costa, "The 'Smart Paradox': Stimulate the deployment of smart grids with effective regulatory instruments," Energy, vol. 69, pp. 96-103, May 2014.

[95] I. J. Perez-Arriaga, J. D. Jenkins, and C. Batlle, "A regulatory framework for an evolving electricity sector: Highlights of the MIT utility of the future study," Economics of Energy \& Environmental Policy, vol. 6, no. 1, pp. 71-92, Jan. 2017.

[96] P. J. Agrell, P. Bogetoft, and M. Mikkers, "Smart-grid investments, regulation and organization," Energy Policy, vol. 52, pp. 656-666, 2013.

[97] R. Shaw, M. Attree, and T. Jackson, "Developing electricity distribution networks and their regulation to support sustainable energy," Energy Policy, vol. 38, no. 10, pp. 5927-5937, Oct. 2010. 
[98] E. Niesten, "Network investments and the integration of distributed generation: Regulatory recommendations for the Dutch electricity industry," Energy Policy, vol. 38, no. 8, pp. 43554362, Aug. 2010.

[99] O. H. Anuta, P. Taylor, D. Jones, T. McEntee, and N. Wade, "An international review of the implications of regulatory and electricity market structures on the emergence of grid scale electricity storage," Renewable and Sustainable Energy Reviews, vol. 38, pp. 489-508, Oct. 2014.

[100] A. Sheikhi Fini, M. Parsa Moghaddam, and M. K. Sheikh-El-Eslami, "An investigation on the impacts of regulatory support schemes on distributed energy resource expansion planning," Renewable Energy, vol. 53, pp. 339-349, May 2013.

[101] B. Shen, G. Ghatikar, Z. Lei, J. Li, G. Wikler, and P. Martin, "The role of regulatory reforms, market changes, and technology development to make demand response a viable resource in meeting energy challenges," Applied Energy, vol. 130, pp. 814-823, Oct. 2014.

[102] S. Ropenus, H. K. Jacobsen, and S. T. Schröder, "Network regulation and support schemes? How policy interactions affect the integration of distributed generation," Renewable Energy, vol. 36, no. 7, pp. 1949-1956, Jul. 2011.

[103] R. Cossent, T. Gómez, and P. Frías, "Towards a future with large penetration of distributed generation: Is the current regulation of electricity distribution ready? Regulatory recommendations under a European perspective," Energy Policy, vol. 37, no. 3, pp. 11451155, Mar. 2009.

[104] G. I. Pereira and P. P. Silva, "Determinants of change in electricity distribution system operators - a review and survey," in 2016 13th International Conference on the European Energy Market (EEM), 2016, vol. 2016-July, pp. 1-5.

[105] J. Markard, "Transformation of Infrastructures: Sector Characteristics and Implications for Fundamental Change," Journal of Infrastructure Systems, vol. 17, no. 3, pp. 107-117, Sep. 2011.

[106] L. Kiesling, "Implications of Smart Grid Innovation for Organizational Models in Electricity Distribution - Handbook of Smart Grid Development," in Smart Grid Handbook, C.-C. Liu, S. McArthur, and S.-J. Lee, Eds. Hoboken: Wiley, 2016, p. 1900.

[107] U. Dubois and R. Saplacan, "Public Service Perspectives on Reforms of Electricity Distribution and Supply: a Modular Analysis.," Annals of Public \& Cooperative Economics, vol. 81, no. 2, pp. 313-356, 2010.

[108] V. Persideanu and V. Rascanu, "Changes in the electrical energy distribution branch," Economics, Management and Financial Markets, vol. 6, no. 1, pp. 555-563, 2011.

[109] H. Tsoukas and D. B. Papoulias, "Managing third-order change: The case of the Public Power Corporation in Greece," Long Range Planning, vol. 38, no. 1, pp. 79-95, 2005.

[110] P. Trygg, J. Toivonen, and P. Järventausta, "Changes of business models in electricity distribution," International Energy Journal, vol. 8, no. 4, pp. 243-248, 2007.

[111] J. Kossahl, J. Kranz, O. Nicky, and L. Kolbe, "A Perception-based Model for Smart Grid Adoption of Distribution System Operators - An Empirical Analysis," in AMCIS 2012 Proceedings, 2012, pp. 1-10. 
[112] B. K. Sovacool, "What are we doing here? Analyzing fifteen years of energy scholarship and proposing a social science research agenda," Energy Research \& Social Science, vol. 1, pp. 129, Mar. 2014.

[113] B. K. Sovacool et al., "Integrating social science in energy research," Energy Research \& Social Science, vol. 6, pp. 95-99, Mar. 2015.

[114] M. Anda and J. Temmen, "Smart metering for residential energy efficiency: The use of community based social marketing for behavioural change and smart grid introduction," Renewable Energy, vol. 67, pp. 119-127, 2014.

[115] G. P. J. Verbong, S. Beemsterboer, and F. Sengers, "Smart grids or smart users? Involving users in developing a low carbon electricity economy," Energy Policy, vol. 52, pp. 117-125, Jan. 2013.

[116] L. Meeus and S. Hadush, "The emerging regulatory practice for new businesses related to distribution grids," no. 2016/02, pp. 1-6, 2016.

[117] A. Nisar, F. Ruiz, and M. Palacios, "Organisational learning, strategic rigidity and technology adoption: Implications for electric utilities and renewable energy firms," Renewable and Sustainable Energy Reviews, vol. 22, pp. 438-445, Jun. 2013.

[118] T. Helms, "Asset transformation and the challenges to servitize a utility business model," Energy Policy, vol. 91, pp. 98-112, Apr. 2016.

[119] C. Cambini, A. Meletiou, E. Bompard, and M. Masera, "Market and regulatory factors influencing smart-grid investment in Europe: Evidence from pilot projects and implications for reform," Utilities Policy, vol. 40, pp. 36-47, Jun. 2016.

[120] European Commission, "Clean Energy for All Europeans," Brussels, 2016.

[121] European Commission, "Directive of the European Parliament and of the Council on common rules for the internal market in electricity (recast)," 2017.

[122] Electric Power Research Institute, "The green grid. Energy savings and carbon emissions reductions enabled by a smart grid," 2008.

[123] IEA, “Technology roadmap - smart grids," Paris, France, 2011.

[124] S. Borenstein, M. Jaske, and A. Rosenfeld, "Dynamic pricing, advanced metering, and demand response in electricity markets," eScholarship Repository, University of California, 2002.

[125] S. J. Rassenti, V. L. Smith, and B. J. Wilson, "Controlling market power and price spikes in electricity networks: Demand-side bidding," Proceedings of the National Academy of Sciences of the United States of America, vol. 100, no. 2998-3003, 2003.

[126] Y. Guo, A. Zeman, and R. Li, "Utility simulation tool for automated energy demand side management," Energy Network, pp. 37-44, 2009.

[127] M. H. Albadi and E. F. El-Saadany, "A summary of demand response in electricity markets," Electric Power Systems Research, vol. 78, pp. 1989-1996, 2008.

[128] C. Roe, S. Meliopoulos, R. Entriken, and S. Chhaya, "Simulated demand response of a residential energy management system," IEEE, pp. 1-6, 2011. 
[129] W. Kempton and J. Tomic, "Vehicle-to-grid power implementation: From stabilizing the grid to supporting large-scale renewable energy," Journal of Power Sources, vol. 144, pp. 280-294, 2005.

[130] Union for the co-ordination of transmission of electricity, "Final report - System disturbance on 4 November 2006," 2006.

[131] F. Zeilinger, "Simulation of the effect of demand side management to the power consumption of households," in 3rd International Youth Conference on Energetics 2011, 2011, pp. 1-8.

[132] DOE, "Report of the DOE power outage study team on electric reliability events of the Summer of $1999, " 2000$.

[133] M. Roozbehani, M. A. Dahleh, and S. K. Mitter, "Volatility of power grids under real-time pricing," LIDS REPORT, pp. 1-14, 2011.

[134] B. Celik, R. Roche, S. Suryanarayanan, D. Bouquain, and A. Miraoui, "Electric energy management in residential areas through coordination of multiple smart homes," Renewable and Sustainable Energy Reviews, vol. 80, pp. 260-275, 2017.

[135] F. Schweppe, R. D. Tabors, J. L. Kirtley, H. R. Outhred, F. H. Pickel, and A. J. Cox, "Homeostatic utilitycontrol," IEEE Transactions on Power Apparatus and Systems, vol. 99, no. 3, pp. 1151-1163, 1980.

[136] C. W. Gellings, "Then and now - The perspective of the man who coined the term 'DSM'," Energy Policy, vol. 24, no. 4, pp. 285-288, 1996.

[137] K. Kostková, L. Omelina, P. Kyčina, and P. Jamrich, "An introduction to load management," Electric Power Systems Research, vol. 95, pp. 184-191, 2013.

[138] S. Karnouskos and T. N. de Holanda, "Simulation of a smart grid city with software agents," in Third UKSim European Symposium on Computer Modeling and Simulation EMS'09. 25-27 Nov., 2009.

[139] R. Teng and T. Yamazaki, "Bit-Watt home system with hybrid power supply," IEEE, vol. 5, pp. 59-63, 2010.

[140] S. Park, H. Kim, H. Moon, J. Heo, and S. Yoon, "Concurrent simulation platform for energyaware smart metering systems," IEEE Transactions on Consumer Electronics, vol. 56, no. 3, pp. 1918-1926, 2010.

[141] N. Gudi, L. Wang, V. Devabhaktuni, and S. S. S. R. Depuru, "Demand response simulation implementing heuristic optimization for home energy management."

[142] A. Molderink, V. Bakker, M. G. C. Bosman, J. L. Hurink, and G. J. M. Smit, "Management and control of domestic smart grid technology," IEEE Transactions on Smart Grid, pp. 1-10, 2010.

[143] A. J. Roscoe and G. Ault, "Supporting high penetrations of renewable generation via implementation of real-time electricity pricing and demand response," IET Renewable Power Generation, vol. 4, no. 4, pp. 369-382, 2010.

[144] P. Miguel, L. Neves, and A. G. Martins, "Methodology to simulate the impact of a large deployment of a residential energy management system in the electricity grid," Electric Power Systems Research, vol. 116, pp. 399-407, 2014.

[145] D. Livengood and R. Larson, "The energy box: Locally automated optimal control of residential electricity usage," Service Science, vol. 1, no. 1, pp. 1-16, 2009. 
[146] P. Miguel, J. Gonçalves, L. Neves, and A. G. Martins, "Using clustering techniques to provide simulation scenarios for the smart grid," Sustainable Cities and Society, vol. 26, pp. 447-455, 2016.

[147] European Parliament, “Decentralised energy systems," 2010.

[148] F. W. Geels, "Technological transitions as evolutionary reconfiguration processes: a multi-level perspective and a case-study," Research Policy, vol. 31, pp. 1257-1274, 2002.

[149] A. Schreuer and D. Weismeier-Sammer, "Energy cooperatives and local ownership in the field of renewable energy technologies: a literature review," 2010.

[150] M. Oteman, M. Wiering, and J.-K. Helderman, "The institutional space of community initiatives for renewable energy: a comparative case study of the Netherlands , Germany and Denmark," Energy, Sustainability and Society, vol. 4, no. 11, 2014.

[151] G. Seyfang, J. J. Park, and A. Smith, "A thousand flowers blooming? An examination of community energy in the UK," Energy Policy, vol. 61, pp. 977-989, 2013.

[152] G. Walker and P. Devine-Wright, "Community renewable energy: What should it mean?," Energy Policy, vol. 36, pp. 497-500, 2008.

[153] L. Okkonen and O. Lehtonen, "Socio-economic impacts of community wind power projects in Northern Scotland,” Renewable Energy, vol. 85, pp. 826-833, 2016.

[154] Ö. Yildiz et al., "Renewable energy cooperatives as gatekeepers or facilitators? Recent developments in Germany and a multidisciplinary research agenda," Energy Research \& Social Science, vol. 6, pp. 59-73, 2015.

[155] International Cooperative Alliance, "Co-operative enterprises build a better world." [Online]. Available: http://ica.coop/. [Accessed: Jul-2017].

[156] E. Viardot, "The role of cooperatives in overcoming the barriers to adoption of renewable energy," Energy Policy, vol. 63, pp. 756-764, 2013.

[157] J. Müller and J. Rommel, "Is there a future role for urban electricity cooperatives? The case of Greenpeace Energy," in Biennial International Workshop "Advances in Energy Studies," 2010.

[158] I. Mignon and A. Rüdinger, "The impact of systemic factors on the deployment of cooperative projects within renewable electricity production - An international comparison," Renewable and Sustainable Energy Reviews, vol. 65, pp. 478-488, 2016.

[159] REScoop, "European Federation of Renewable Energy Cooperatives," 2017. [Online]. Available: https://rescoop.eu/facts-figures-0. [Accessed: Jul-2017].

[160] S. Hall, T. J. Foxon, and R. Bolton, "Financing the civic energy sector: How financial institutions affect ownership models in Germany and the United Kingdom," Energy Research \& Social Science, vol. 12, pp. 5-15, 2016.

[161] UNDP Croatia, "Inovative financing and business models for RES.," in Joint IRENA-ENC workshop on renewable energy. Energy Community, 2016, no. March.

[162] M. Barry and R. Chapman, "Distributed small-scale wind in New Zealand: Advantages, barriers and policy support instruments," Energy Policy, vol. 37, pp. 3358-3369, 2009. 
[163] J. C. Rogers, E. A. Simmons, I. Convery, and A. Weatherall, "Public perceptions of opportunities for community-based renewable energy projects," Energy Policy, vol. 36, pp. 4217-4226, 2008.

[164] C. R. Warren and M. Mcfadyen, "Does community ownership affect public attitudes to wind energy? A case study from south-west Scotland," Land Use Policy, vol. 27, pp. 204-213, 2010.

[165] S. Breukers and M. Wolsink, "Wind power implementation in changing institutional landscapes: An international comparison," Energy Policy, vol. 35, no. 5, pp. 2737-2750, 2007.

[166] S. Agterbosch, W. Vermeulen, and P. Glasbergen, "Implementation of wind energy in the Netherlands: The importance of the social-institutional setting," Energy Policy, vol. 32, no. 18, pp. 2049-2066, 2004.

[167] F. D. Musall and O. Kuik, "Local acceptance of renewable energy - A case study from southeast Germany," Energy Policy, vol. 39, no. 6, pp. 3252-3260, 2011.

[168] D. Toke, S. Breukers, and M. Wolsink, "Wind power deployment outcomes: How can we account for the differences?," Renewable and Sustainable Energy Reviews, vol. 12, no. 4, pp. 1129-1147, 2008.

[169] T. Kaphengst and E. K. Velten, "Energy transition and behavioural change in rural areas - The role of energy cooperatives," no. 60. 2014.

[170] International Labour Office, Providing clean energy and energy access through cooperatives. Geneva: International Labour Office (ILO), Cooperatives Unit (ENT/ COOP), Green Jobs Program, 2013.

[171] E. Barata, "Solid waste policy in Portugal: An environmental input output approach," Keele University, School of Politics International Relations and the Environment, Keele, UK, 2002.

[172] W. Leontief, "National income, economic structure, and environmental externalities," in The measurement of economic and social performance, NBER, 1973, pp. 565-576.

[173] W. W. Leontief and M. Hoffenberg, The economic effects of disarmament. 1961.

[174] W. Leontief, The future of nonfuel minerals in the United States and world economy: Inputoutput projections, 1980-2030. Lexington Books, 1983, p. 482.

[175] W. Leontief and F. Duchin, The future impact of automation on workers. Oxford University Press, 1986.

[176] M. Ciaschini, "Input-output analysis: an introduction.” 1988.

[177] F. Førsund, "Input-output models, national economic models, and the environment," Handbook of National Resource and Energy Economics, vol. 1, pp. 325-341, 1985.

[178] P. J. G. Pearson, "Proactive energy-environment policy strategies: a role for input-output analysis?," Environment and Planning A - International Journal of Urban and Regional Research, vol. 21, no. 10, pp. 1329-1348, 1989.

[179] R. O'Connor and E. W. Henry, "Input-output analysis and its applications." Charles Griffin and Company, 1975.

[180] L. M. G. Cruz, "A Portuguese energy-economy-environment input-output model: policy applications," Keele University, School of Politics International Relations and the Environment, Keele, UK, 2002. 
[181] V. Albino and S. Kühtz, "Enterprise input-output model for local sustainable development - the case of a tiles manufacturer in Italy," Resources, Conservation and Recycling, vol. 41, pp. 165176, 2004.

[182] M. Matsumoto and J. Fujimoto, "The development of an enterprise input output model and its application to industrial environmental management," Journal of Applied Input-Output Analysis, vol. 13\&14, pp. 123-143, 2008.

[183] M. Lenzen and S. Lundie, "Constructing enterprise input-output tables - a case study of New Zealand dairy products," Journal of Economic Structures, vol. 1, no. 6, pp. 1-15, 2012.

[184] D. Hawdon and P. Pearson, "Input-output simulations of energy, environment, economy interactions in the UK," Energy Economics, vol. 17, no. 1, pp. 73-86, 1995.

[185] J. H. Cumberland, "A regional interindustry model for analysis of development objectives," Papers of the Regional Science Association, vol. 17, no. 1, pp. 65-94, 1966.

[186] J. Munksgaard and K. A. Pedersen, "CO2 accounts for open economies: producer or consumer responsibility?," Energy Policy, vol. 29, pp. 327-334, 2001.

[187] C. Yuan, S. Liu, and N. Xie, "The impact on chinese economic growth and energy consumption of the Global Financial Crisis: An input - output analysis," Energy, vol. 35, no. 4, pp. 18051812, 2010.

[188] X. Tang, B. Zhang, L. Feng, S. Snowden, and M. Höök, "Net oil exports embodied in China's international trade: An input-output analysis," Energy, vol. 48, pp. 464-471, 2012.

[189] I. Logar and J. C. J. M. van den Bergh, "The impact of peak oil on tourism in Spain: An inputoutput analysis of price, demand and economy-wide effects," Energy, vol. 54, pp. 155-166, 2013.

[190] P. W. Gay and J. L. R. Proops, "Carbon-dioxide production by th UK economy: an input output assessment," Applied Energy, vol. 44, no. 2, pp. 113-130, 1993.

[191] J. B. Cruz, R. R. Tan, A. B. Culaba, and J.-anne Ballacillo, "A dynamic input-output model for nascent bioenergy supply chains," Applied Energy, vol. 86, p. S86-S94, 2009.

[192] B. Zhang, H. Qiao, Z. M. Chen, and B. Chen, "Growth in embodied energy transfers via China's domestic trade: Evidence from multi-regional input-output analysis," Applied Energy, vol. 184, pp. 1093-1105, 2016.

[193] W.-S. Chung, S. Tohno, and Y. S. Shim, "An estimation of energy and GHG emission intensity caused by energy consumption in Korea: An energy $1 \mathrm{O}$ approach," Applied Energy, vol. 86, pp. 1902-1914, 2009.

[194] W.-S. Chung, S. Tohno, and K.-H. Choi, "Socio-technological impact analysis using an energy IO approach to GHG emissions issues in South Korea," Applied Energy, vol. 88, pp. 37473758, 2011.

[195] S. Chen and B. Chen, "Urban energy consumption: Different insights from energy flow analysis, input--output analysis and ecological network analysis," Applied Energy, vol. 138, pp. 99-107, Jan. 2015.

[196] M. Lenzen and C. J. Dey, "Economic, energy and greenhouse emissions impacts of some consumer choice, technology and government outlay options," Energy Economics, vol. 24, pp. 377-403, 2002. 
[197] J. Nässén, J. Holmberg, A. Wadeskog, and M. Nyman, "Direct and indirect energy use and carbon emissions in the production phase of buildings: An input-output analysis," Energy, vol. 32, pp. 1593-1602, 2007.

[198] Y.-H. Huang and J.-H. Wu, "Analyzing the driving forces behind $\mathrm{CO} 2$ emissions and reduction strategies for energy-intensive sectors in Taiwan, 1996-2006," Energy, vol. 57, pp. 402-411, 2013.

[199] S. Faucheaux and F. Levarlet, "Chapter 73: Energy-economy-environment models," in Handbook of Environmental and Resource Economics, J. C. J. M. van den Bergh, Ed. Edward Elgar, 1999, p. 23.

[200] Y. Moriguchi, Y. Kondo, and H. Shimizu, "Analysing the life cycle impacts of cars: The case of CO2," Industry and Environment, vol. 16, no. 1-2, pp. 42-45, 1993.

[201] H. S. Matthews and M. J. Small, "Extending the boundaries of life-cycle assessment through environmental economic input-output models," Journal of Industrial Ecology, vol. 4, no. 3, pp. 7-10, 2000.

[202] S. Suh, "Functions, commodities and environmental impacts in an ecological-economic model," Ecological Economics, vol. 48, pp. 451-467, 2004.

[203] S. Suh and G. Huppes, "Methods for life cycle inventory of a product," Journal of Cleaner Production, vol. 13, pp. 687-697, 2005.

[204] G. Rebitzer et al., "Life cycle assessment. Part 1: Framework, goal and scope definition, inventory analysis, and applications," Environment International, vol. 30, pp. 701-720, 2004.

[205] V. Narayanaswamy, J. Altham, R. V. Berkel, and M. Mcgregor, "A primer on environmental life cycle assessment (LCA) for Australian grains," Framework, no. September. Curtin University of Technology, Centre of Excellence in Cleaner Production, 2002.

[206] J. B. Guinée et al., Life cycle assessment. Operational guide to the ISO standards. Leiden University, Centre of Environmental Science, 2001.

[207] C. Flemmer and R. Flemmer, "The relationship between environmental sustainability and input output analysis of the New Zealand dairy farming sector," in ANZSEE conference reinventing sustainability: A climate for change, 2007.

[208] S. Nakamura and Y. Kondo, "Waste input-output analysis: concepts and application to industrial Ecology," Journal of Industrial Ecology, vol. 13, no. 5, pp. 835-836, 2009.

[209] H. K. Jeswani, A. Azapagic, P. Schepelmann, and M. Ritthoff, "Options for broadening and deepening the LCA approaches," Journal of Cleaner Production, vol. 18, pp. 120-127, 2010.

[210] C. T. Hendrickson, L. B. Lave, and S. H. Matthews, "Environmental life cycle assessment of goods and services. An input-output approach," Direct, no. April. RFF Press. Resources for the Future, p. 260, 2006.

[211] G. Majeau-bettez, A. H. Strømman, and E. G. Hertwich, "Evaluation of process- and inputoutput based life cycle inventory data with regard to truncation and aggregation issues," Environmental Science \& Technology, vol. 45, pp. 10170-10177, 2011.

[212] H. A. Udo de Haes, R. Heijungs, S. Suh, and G. Huppes, "Three strategies to overcome the limitations of life-cycle assessment," Journal of Industrial Ecology, vol. 8, no. 3, pp. 19-32, 2004. 
[213] S. Suh et al., "System boundary selection in life-cycle inventories using hybrid approaches," Environmental Science \& Technology, vol. 38, no. 3, pp. 657-664, 2004.

[214] C.-H. Lee and H.-W. Ma, "Improving the integrated hybrid LCA in the upstream scope 3 emissions inventory analysis," The International Journal of Life Cycle Assessment, vol. 18, pp. 17-23, 2013.

[215] A. L. Carvalho, C. H. Antunes, F. Freire, and C. O. Henriques, "A hybrid input-output multiobjective model to assess economic-energy-environment trade-offs in Brazil," Energy, vol. 82, pp. 769-785, 2015.

[216] G. B. Dantzig, Linear programming and extensions. Santa Monica, The Rand Corporation, 1963.

[217] D. Albers and C. Reid, "An interview with George B. Dantzig: The father of linear programming," The College Mathematics Journal, vol. 17, pp. 229-234, 1986.

[218] P. B. Clark and L. Taylor, "Dynamic input-output planning with optimal end conditions: The case of Chile," Economics of Planning, vol. 11, no. 1-2, pp. 10-30, 1971.

[219] H. G. Bergendorfj, P. B. Clark, and L. Taylor, "Welfare gains from optimization in dynamic planning models," Economics of Planning, vol. 13, no. 1-2, pp. 75-90, 1973.

[220] R. Dorfman, P. A. Samuelson, and R. M. Solow, "Linear programming and economic analysis," The Journal of Business, vol. 32, no. 1, pp. 85-86, 1959.

[221] A. A. Ebiefung and M. M. Kostreva, "The generalized Leontief input-output model and its application to the choice of new technology," Annals of Operations Research, vol. 44, pp. 161172, 1993.

[222] E. Zhu, M.-K. Kim, and T. R. Harris, "Input-output analysis, linear programming and modified multipliers," in Southern Agricultural Economics Association Annual Meeting. Atlanta, Georgia, USA., 2009, pp. 1-17.

[223] R. Jackson and A. Murray, "Alternative input-output matrix updating formulations," Economic Systems Research, vol. 16, no. 2, pp. 135-148, 2004.

[224] A. H. Strømman, "A multi-objective assessment of input-output matrix updating methods," Economic Systems Research, vol. 21, no. 1, pp. 81-88, 2009.

[225] F. Muller, Energy and environment in interregional input-output models. Kluwer Academic Publishers, 1979.

[226] T. K. Moulik, B. H. Dholakia, R. H. Dholakia, K. V. Ramani, and P. R. Shukla, "Energy planning in India: the relevance of regional planning for natural policy," Energy Policy, vol. 20, no. 9, pp. 836-846, 1992.

[227] D. Hristu-Varsakelis, S. Karagianni, M. Pempetzoglou, and A. Sfetsos, "Optimizing production with energy and GHG emission constraints in Greece: An input-output analysis," Energy Policy, vol. 38, pp. 1566-1577, 2010.

[228] C.-J. Cho, "The economic-energy-environmental policy problem: an application of the interactive multiobjective decision method for Chungbuk Province," Journal of Environmental Management, vol. 56, pp. 119-131, 1999.

[229] G. J. Y. Hsu and F.-Y. Chou, "Integrated planning for mitigating $\mathrm{CO} 2$ emissions in Taiwan: a multi-objective programming approach," Energy Policy, vol. 28, pp. 519-523, 2000. 
[230] M. K. Kravtsov and A. V. Pashkevich, "A multicriteria approach to optimization of the gross domestic product," Autom Remote Control, vol. 65, no. 2, pp. 337-345, 2004.

[231] T.-yieth Chen, "The impact of mitigating $\mathrm{CO} 2$ emissions on Taiwan's economy," Energy Economics, vol. 23, pp. 141-151, 2001.

[232] C. Oliveira and C. H. Antunes, "A multi-objective multi-sectoral economy-energy-environment model: Application to Portugal," Energy, vol. 36, pp. 2856-2866, 2011.

[233] C. Oliveira and C. H. Antunes, "A multiple objective model to deal with economy-energyenvironment interactions," European Journal Of Operational Research, vol. 153, pp. 370-385, 2004.

[234] A. L. Carvalho, C. H. Antunes, F. Freire, and C. O. Henriques, "A multi-objective interactive approach to assess economic-energy-environment trade-offs in Brazil," Renewable and Sustainable Energy Reviews, vol. 54, pp. 1429-1442, 2016.

[235] S. Chang and M. Juang, "Decision analysis on CO2 reduction for industrial and energy sectors - an FMOLP approach," in Conference on East Asian Environmental and Resource Economics and Policy - Institute of Economics. Taipei, 1998.

[236] S.-li Chang, "Decision analysis of sustainable energy development and GHG mitigation in Taiwan - A fuzzy multiobjective programming approach," in 28th Annual IAEE International Conference. Taipei, Taiwan, 2005, pp. 1-20.

[237] A. R. Borges and C. H. Antunes, "A fuzzy multiple objective decision support model for energyeconomy planning," European Journal Of Operational Research, vol. 145, pp. 304-316, 2003.

[238] C. O. Henriques and C. H. Antunes, "Interactions of economic growth, energy consumption and the environment in the context of the crisis - A study with uncertain data," Energy, vol. 48, pp. 415-422, 2012.

[239] A. L. Carvalho, C. H. Antunes, and F. Freire, "Economic-energy-environment analysis of prospective sugarcane bioethanol production in Brazil," Applied Energy, vol. 181, pp. 514-526, 2016.

[240] C. Kennedy, J. Cuddihy, and J. Engel-yan, "The changing metabolism of cities," Journal of Industrial Ecology, vol. 11, no. 2, pp. 43-59, 2007.

[241] A. Stephan, R. H. Crawford, and K. de Myttenaere, "Multi-scale life cycle energy analysis of a low-density suburban neighbourhood in Melbourne, Australia," Building and Environment, vol. 68, pp. 35-49, 2013.

[242] UN, "World Urbanization Prospects The 2011 Revision." United Nations, 2011.

[243] United Nations, World Urbanization Prospects The 2014 Revision. New York: United Nations (ST/ESA/SER.A/366), 2015.

[244] A. M. Omer, "Energy, environment and sustainable development," Renewable and Sustainable Energy Reviews, vol. 12, no. 9, pp. 2265-2300, 2008.

[245] United Nations, "World Cities Report 2016," 2016.

[246] C. Kennedy et al., "Greenhouse gas emissions from global cities," Environmental Science \& Technology, vol. 43, no. 19, pp. 7297-7302, 2009.

[247] UN, "World Urbanization Prospects: The 2007 revision." 2007. 
[248] M. Breheny, "The contradictions of the compact city," in Sustainable Development and Urban Form, 1992.

[249] M. Jenks, E. Burton, and K. Williams, Eds., The compact city: A sustainable urban form? London: E \& FN Spon, 1996.

[250] M. R. . Doughty and G. P. Hammond, "Sustainability and the built environment at and beyond the city scale," Building and Environment, vol. 39, no. 10, pp. 1223-1233, Oct. 2004.

[251] Y. R. Jabareen, "Sustainable urban forms: their typologies, models, and concepts," Journal of Planning Education and Research, vol. 26, no. 1, pp. 38-52, Sep. 2006.

[252] K. Williams, “Urban form and infrastructure: a morphological review," 2014.

[253] L. F. Cabeza, L. Rincón, V. Vilariño, G. Pérez, and A. Castell, "Life cycle assessment (LCA) and life cycle energy analysis (LCEA) of buildings and the building sector: a review," Renewable and Sustainable Energy Reviews, vol. 29, pp. 394-416, 2014.

[254] P. Rickwood, G. Glazebrook, and G. Searle, "Urban structure and energy - A review," Urban Policy and Research, vol. 26, no. 1, pp. 57-81, 2008.

[255] J. E. Anderson, G. Wulfhorst, and W. Lang, "Energy analysis of the built environment - A review and outlook," Renewable and Sustainable Energy Reviews, vol. 44, pp. 149-158, 2015.

[256] O. Ortiz, F. Castells, and G. Sonnemann, "Sustainability in the construction industry: A review of recent developments based on LCA," Construction and Building Materials, vol. 23, no. 1, pp. 28-39, Jan. 2009.

[257] A. Sharma, A. Saxena, M. Sethi, and V. Shree, "Life cycle assessment of buildings: A review," Renewable and Sustainable Energy Reviews, vol. 15, no. 1, pp. 871-875, Jan. 2011.

[258] A. Okeil, "A holistic approach to energy efficient building forms," Energy and Buildings, vol. 42, no. 9, pp. 1437-1444, 2010.

[259] R. Ewing and F. Rong, "The impact of urban form on US residential energy use," Housing Policy Debate, vol. 19, no. 1, pp. 1-30, 2008.

[260] A. Stephan, R. H. Crawford, and K. de Myttenaere, "A comprehensive assessment of the life cycle energy demand of passive houses," Applied Energy, vol. 112, pp. 23-34, 2013.

[261] J. Bastos, S. A. Batterman, and F. Freire, "Life-cycle energy and greenhouse gas analysis of three building types in a residential area in Lisbon," Energy and Buildings, vol. 69, pp. 344-353, 2014.

[262] K. Maat and H. J. P. Timmermans, "Influence of the residential and work environment on car use in dual-earner households," Transportation Research Part A: Policy and Practice, vol. 43, no. 7, pp. 654-664, 2009.

[263] P. Newton and D. Meyer, "The Determinants of Urban Resource Consumption," Environment and Behavior, vol. 44, no. 1, pp. 107-135, Dec. 2010.

[264] X. (Jason) Cao, "Examining the impacts of neighborhood design and residential self-selection on active travel: a methodological assessment," Urban Geography, vol. 36, no. 2, pp. 236-255, 2015.

[265] H. Lund, B. Moller, B. V. Mathiesen, and A. Dyrelund, "The role of district heating in future renewable energy systems," Energy, vol. 35, pp. 1381-1390, 2010. 
[266] B. Rezaie and M. A. Rosen, "District heating and cooling: review of technology and potential enhancements," Applied Energy, vol. 93, pp. 2-10, 2012.

[267] H. Lund et al., "4th generation district heating (4GDH) Integrating smart thermal grids into future sustainable energy systems," Energy, vol. 68, pp. 1-11, 2014.

[268] J. R. Kenworthy and F. B. Laube, "Automobile dependence in cities: An international comparison of urban transport and land use patterns with implications for sustainability," Environmental Impact Assessment Review, vol. 16, no. 4-6, pp. 279-308, 1996.

[269] S. Handy, "Methodologies for exploring the link between urban form and travel behavior," Transportation Research Part D: Transport and Environment, vol. 1, no. 2, pp. 151-165, Dec. 1996.

[270] D. A. Badoe and E. J. Miller, "Transportation - land use interaction: empirical findings in North America and their implications for modeling," Transportation Research - D, vol. 5, no. 4, pp. 235-263, 2000.

[271] D. Stead and S. Marshall, "The Relationships between Urban Form and Travel Patterns . An International Review and Evaluation," European Journal of Transport and Infrastructure Research, vol. 1, no. 2, pp. 11-141, 2001.

[272] J. Woodcock, D. Banister, P. Edwards, A. M. Prentice, and I. Roberts, "Energy and transport," Lancet, vol. 370, no. 9592, pp. 1078-1088, 2007.

[273] G. Mitchell, A. Hargreaves, A. Namdeo, and M. Echenique, "Land use, transport, and carbon futures: the impact of spatial form strategies in three UK urban regions," Environment and Planning A, vol. 43, no. 9, pp. 2143-2163, 2011.

[274] H. B. Dulal, G. Brodnig, and C. G. Onoriose, "Climate change mitigation in the transport sector through urban planning: A review," Habitat International, vol. 35, no. 3, pp. 494-500, 2011.

[275] F. Karagulian et al., "Contributions to cities' ambient particulate matter (PM): A systematic review of local source contributions at global level," Atmospheric Environment, vol. 120, pp. 475-483, 2015.

[276] M. J. Nieuwenhuijsen and H. Khreis, "Car free cities: Pathway to healthy urban living," Environment International, vol. 94, pp. 251-262, 2016.

[277] P. Næss, "Urban form, sustainability and Health: The case of Greater Oslo," European Planning Studies, vol. 4313, pp. 1-20, 2013.

[278] E. J. Gago, J. Roldan, R. Pacheco-Torres, and J. Ordóñez, "The city and urban heat islands: A review of strategies to mitigate adverse effects," Renewable and Sustainable Energy Reviews, vol. 25, pp. 749-758, 2013.

[279] J. A. Patz, D. Campbell-Lendrum, T. Holloway, and J. A. Foley, "Impact of regional climate change on human health," Nature, vol. 438, pp. 310-317, 2005.

[280] K. Laaidi et al., "The impact of heat islands on mortality in Paris during the August 2003 heatwave," Environmental Health Perspectives, vol. 120, no. 2, pp. 254-259, 2012.

[281] N. B. Grimm et al., "Global change and the ecology of cities," Science, vol. 319, no. 5864, pp. 756-760, 2008.

[282] J. A. Voogt and T. R. Oke, "Thermal remote sensing of urban climates," Remote Sensing of Environment, vol. 86, pp. 370-384, 2003. 
[283] M. Stathopoulou and C. Cartalis, "Daytime urban heat islands from Landsat ETM+ and Corine land cover data: An application to major cities in Greece," Solar Energy, vol. 81, no. 3, pp. 358368, 2007.

[284] C. Aniello, K. Morgan, A. Busbey, and L. Newland, "Mapping micro-urban heat islands using LANDSAT TM and a GIS," Computers \& Geosciences, vol. 21, no. 8, pp. 965-969, Oct. 1995.

[285] C. Rosenzweig, W. D. Solecki, L. Parshall, M. Chopping, G. Pope, and R. Goldberg, "Characterizing the urban heat island in current and future climates in New Jersey," Global Environmental Change Parte B: Environmental Hazards, vol. 6, no. 1, pp. 51-62, 2005.

[286] L. Zhao, X. Lee, R. B. Smith, and K. Oleson, "Strong contributions of local background climate to urban heat islands," Nature, vol. 511, pp. 216-219, Jul. 2014.

[287] A. Dimoudi and M. Nikolopoulou, "Vegetation in the urban environment: Microclimatic analysis and benefits," Energy and Buildings, vol. 35, no. 1, pp. 69-76, 2003.

[288] A. Onishi, X. Cao, T. Ito, F. Shi, and H. Imura, "Evaluating the potential for urban heat-island mitigation by greening parking lots," Urban Forestry and Urban Greening, vol. 9, no. 4, pp. 323332, 2010.

[289] F. Hölker et al., "The dark side of light: a transdisciplinary research agenda for light pollution policy," Ecology And Society, vol. 15, no. 4, 2010.

[290] K. Painter, "The influence of street lighting improvements on crime, fear and pedestrian street use, after dark," Landscape and Urban Planning, vol. 35, pp. 193-201, 1996.

[291] M. Kostic and L. Djokic, "Recommendations for energy efficient and visually acceptable street lighting," Energy, vol. 34, pp. 1565-1572, 2009.

[292] K. Narisada and D. Schreude, Light pollution handbook. Springer Netherlands, 2004.

[293] F. Li, D. Chen, X. Song, and Y. Chen, "LEDs: a promising energy-saving light source for road lighting," in Power and Energy Engineering Conference, 2009. APPEEC 2009. Asia-Pacific, 2009.

[294] X. Long, R. Liao, and J. Zhou, "Development of street lighting system-based novel highbrightness LED modules," IET Optoelectronics, vol. 3, no. 1, pp. 40-46, 2009.

[295] X. H. Lee, I. Moreno, and C. C. Sun, "High-performance LED street lighting using microlens arrays," Opt Express, vol. 21, no. 9, pp. 10612-21, 2013.

[296] R. Müllner and A. Riener, "An energy efficient pedestrian aware smart street lighting system," International Journal of Pervasive Computing and Communications, vol. 7, no. 2, pp. 147-161, 2011.

[297] F. Leccese, "Remote-control system of high efficiency and intelligent street lighting using a ZigBee network of devices and sensors," IEEE Transactions on Power Delivery, vol. 28, no. 1, pp. 21-28, 2013.

[298] M. A. D. Costa, G. Costa, A. S. dos Santos, L. Schuch, and J. R. Pinheiro, "A high efficiency autonomous street lighting system based on solar energy and LEDs," in 2009 Brazilian Power Electron. Conf., IEEE, 2009, 2009.

[299] J. Lagorse, D. Paire, and A. Miraoui, "Sizing optimization of a stand-alone street lighting system powered by a hybrid system using fuel cell, PV and battery," Renewable Energy, vol. 34, pp. 683-691, 2009. 
[300] D. Radulovic, S. Skok, and V. Kirincic, "Energy efficiency public lighting management in the cities," Energy, vol. 36, pp. 1908-1915, 2011.

[301] J. Heinonen and S. Junnila, "Implications of urban structure on carbon consumption in metropolitan areas," Environmental Research Letters, vol. 6, no. 1, p. 014018, Jan. 2011.

[302] C. Bauer, J. Hofer, H.-J. Althaus, A. Duce, and A. Simons, "The environmental performance of current and future passenger vehicles: Life cycle assessment based on a novel scenario analysis framework," Applied Energy, vol. 157, pp. 871-883, 2015.

[303] S. Barles, "Urban Metabolism of Paris and Its Region," Journal of Industrial Ecology, vol. 13, no. 6 , pp. 898-913, Dec. 2009

[304] C. Kennedy, S. Pincetl, and P. Bunje, "The study of urban metabolism and its applications to urban planning and design.," Environmental pollution (Barking, Essex : 1987), vol. 159, no. 8-9, pp. 1965-73, 2011.

[305] M. Chester, M. J. Nahlik, A. M. Fraser, M. A. Kimball, and V. M. Garikapati, "Integrating lifecycle environmental and economic assessment with transportation and land use planning," Environmental Science and Technology, vol. 47, no. 21, pp. 12020-12028, 2013.

[306] J. Bastos, S. A. Batterman, and F. Freire, "Significance of mobility in the life-cycle assessment of buildings," Building Research \& Information, pp. 1-30, 2015.

[307] H. Weisz and J. K. Steinberger, "Reducing energy and material flows in cities," Current Opinion in Environmental Sustainability, vol. 2, no. 3, pp. 185-192, Aug. 2010.

[308] S. Pincetl and P. Bunje, "Potential Targets and Benefits for Sustainable Communities Research, Development, and Demonstration Funded by the PIER Program," no. June, 2009.

[309] N. Codoban and C. A. Kennedy, "Metabolism of Neighborhoods," Journal of Urban Planning and Development, no. March, pp. 21-31, 2008.

[310] M. Lotteau, P. Loubet, M. Pousse, E. Dufrasnes, and G. Sonnemann, "Critical review of life cycle assessment (LCA) for the built environment at the neighborhood scale," Building and Environment, vol. 93, no. 2, pp. 165-178, 2015.

[311] L. Cruz, E. Barata, J.-P. Ferreira, and F. Freire, "Greening transportation and parking at University of Coimbra," International Journal of Sustainability in Higher Education, vol. 18, no. 1, pp. 23-38, 2017.

[312] E. Verhoef, P. Nijkamp, and P. Rietveld, "Second-best regulation of road transport externalities," Journal of transport economics and policy, vol. 29, no. 2, pp. 147-167, 1995.

[313] E. Barata, L. Cruz, and J.-P. Ferreira, "Parking at the UC campus: Problems and solutions," Cities, vol. 28, no. 5, pp. 406-413, 2011.

[314] R. Ewing, "Is Los Angeles-style sprawl desirable?," Journal of the American Planning Association, vol. 63, no. 1, pp. 107-126, 1997.

[315] J. Ferreira, "How commuting shapes the urban economies and the environment: a commuting satellite account applied to the Lisbon Metropolitan Area," University of Coimbra, Portugal, 2016.

[316] E. A. Haddad, G. J. D. Hewings, A. A. Porsse, E. S. V. Leeuwen, and R. S. Vieira, "The underground economy: Tracking the higher-order economic impacts of the São Paulo Subway System," Transportation Research Part A, vol. 73, pp. 18-30, 2015. 
[317] G. J. D. Hewings, "Economic interdependence within the Chicago metropolitan area: A Miyazawa analysis," Journal of Regional Science, vol. 41, no. 2, pp. 195-217, 2001.

[318] S. Malpezzi, "Housing prices, externalities, and regulation in US metropolitan areas," Journal of Housing Research, vol. 7, no. 2, pp. 209-241, 1996.

[319] I. Muñiz and A. Galindo, "Urban form and the ecological footprint of commuting. The case of Barcelona," Ecological Economics, vol. 55, pp. 499-514, 2005.

[320] J.-P. Ferreira, P. Ramos, L. Cruz, and E. Barata, "The opportunity costs of commuting: the value of a commuting satellite account framework with an example from Lisbon Metropolitan Area," Economic Systems Research, 2017.

[321] J.-P. Ferreira, P. Ramos, L. Cruz, and E. Barata, "Modeling commuting patterns in a multiregional input-output framework: impacts of an 'urban re-centralization' scenario," Journal of Geographical Systems, vol. 19, pp. 301-317, 2017.

[322] UN, "Transforming our world: the 2030 Agenda for Sustainable Development," 2015.

[323] G. Ewing and E. Sarigöllü, "Assessing consumer preferences for clean-fuel vehicles: A discrete choice experiment," Journal of Public Policy \& Marketing, vol. 19(1), no. I, pp. 106-118, 2000.

[324] M. K. Hidrue, G. R. Parsons, W. Kempton, and M. P. Gardner, "Willingness to pay for electric vehicles and their attributes," Resource and Energy Economics, vol. 33(3), no. 3, pp. 686-705, Sep. 2011.

[325] J. Hevelston, Y. Liu, E. Mcdonnell, E. Fuchs, E. Klampfl, and J. J. Michalek, "Will subsidies drive electric vehicle adoption? Measuring consumer preferences in the U.S. and China," Transportation Research Part A: Policy and Practice, vol. 73, pp. 96-112, 2015.

[326] D. Diamond, "The impact of government incentives for hybrid-electric vehicles: Evidence from US states," Energy Policy, vol. 37, no. 3, pp. 972-983, Mar. 2009.

[327] C. R. Bhat, S. Sen, and N. Eluru, "The impact of demographics, built environment attributes, vehicle characteristics, and gasoline prices on household vehicle holdings and use," Transportation Research Part B: Methodological, vol. 43, no. 1, pp. 1-18, Jan. 2009.

[328] S. Borthwick, "Persuading Scottish drivers to buy low emission cars? The potential role of green taxation measures. Transport Research Institute, Edinburgh Napier University," in Paper presented at 8th Annual Scottish Transport Applications and Research Conference, 2012.

[329] W. Sierzchula, S. Bakker, K. Maat, and B. V. Wee, "The influence of financial incentives and other socio-economic factors on electric vehicle adoption," Energy Policy, vol. 68, pp. 183-194, 2014.

[330] J. Whitehead, J. P. Franklin, and S. Washington, "The impact of a congestion pricing exemption on the demand for new energy efficient vehicles in Stockholm," Transportation Research Part A: Policy and Practice, vol. 70, pp. 24-40, 2014.

[331] S. L. Mabit and M. Fosgerau, "Demand for alternative-fuel vehicles when registration taxes are high," Transportation Research Part D: Transport and Environment, vol. 16(3), no. 3, pp. 225231, May 2011.

[332] K. S. Gallagher and E. J. Muehlegger, "Giving green to get green? The effect of incentives and ideology on hybrid vehicle adoption," Journal of Environmental Economics and Management, vol. 61.1, pp. 1-15, 2007. 
[333] A. Riggieri, "The impact of hybrid electric vehicles on demand and the determinants of hybridvehicle adoption. PhD thesis, School of Public Policy, Georgia Institute of Technology," Georgia Institute of Technology, 2011.

[334] D. Potoglou and P. S. Kanaroglou, "Household demand and willingness to pay for clean vehicles," Transportation Research Part D: Transport and Environment, vol. 12, no. 4, pp. 264274, Jun. 2007.

[335] N. Novemsky, R. Dhar, N. Schwarz, and I. Simonson, "Preference fluency in choice," Journal of Marketing Research, vol. 44(3), no. 3, pp. 347-356, 2007.

[336] A. Garling and J. Thogersen, "Marketing of electric vehicles," Business Strategy and the Environment, vol. 10, no. 1999, pp. 53 -65, 2001.

[337] M. Steiner, R. Helm, and A. Szelig, "Preference measurement and unacceptable attribute levels. University of Regensburg Working Papers in Business, Economics and Management Information Systems." 2011.

[338] T. Zhang, S. Gensler, and R. Garcia, "A study of the diffusion of alternative fuel vehicles: An agent-based modeling approach," Journal of Product Innovation Management, vol. 28, pp. 152168, 2011.

[339] K. S. Kurani, T. Turrentine, and D. Sperling, "Testing electric vehicle demand in hybrid households using a reflexive survey," Transportation Research Part D: Transport and Environment, vol. 1, pp. 131-150, 1996.

[340] S. Beggs, S. Cardell, and J. Hausman, "Assessing the potential demand for electric cars," Journal of Econometrics, vol. 16, pp. 1-19, 1981.

[341] D. S. Bunch, T. F. Golob, and G. P. Occhiuzzo, "Demand for clean-fuel vehicles in California: A discrete-choice stated preference pilot project," Transportation Research Part A: Policy and Practice, vol. 27A (3), no. 3, pp. 237-253, 1993.

[342] R. Segal, "Forecasting the market for electric vehicles in California using conjoint analysis," The Energy Journal, vol. 16 (3), no. 3, pp. 89-111, Jul. 1995.

[343] D. Brownstone, D. S. Bunch, T. F. Golob, and W. Ren, "A transactions choice model for forecasting demand for alternative-fuel vehicles," Research in Transportation Economics, vol. 4, pp. 87-129, 1996.

[344] E. Chéron and M. Zins, "Electric vehicle purchasing intentions: The concern over battery charge duration," Transportation Research Part A: Policy and Practice, vol. 31(3), no. 3, pp. 235-243, 1997.

[345] F. Eggers and F. Eggers, "Where have all the flowers gone? Forecasting green trends in the automobile industry with a choice-based conjoint adoption model," Technological Forecasting \& Social Change, vol. 78(1), pp. 51-62, 2011.

[346] A. Ziegler, "Individual characteristics and stated preferences for alternative energy sources and propulsion technologies in vehicles: A discrete choice analysis for Germany," Transportation Research Part A: Policy and Practice, vol. 46, no. 8, pp. 1372-1385, Oct. 2012.

[347] J. Axsen, C. Orlebar, and S. Skippon, "Social influence and consumer preference formation for pro-environmental technology: The case of a U.K. workplace electric-vehicle study," Ecological Economics, vol. 95, pp. 96-107, 2013. 
[348] A. F. Jensen, E. Cherchi, and S. L. Mabit, "On the stability of preferences and attitudes before and after experiencing an electric vehicle," Transportation Research Part D: Transport and Environment, vol. 25, pp. 24-32, Dec. 2013.

[349] A. Hackbarth and R. Madlener, "Willingness-to-pay for alternative fuel vehicle characteristics: A stated choice study for Germany," Transportation Research Part A: Policy and Practice, vol. 85, pp. 89-111, 2016.

[350] Y. Zhang, Y. Yu, and B. Zou, "Analyzing public awareness and acceptance of alternative fuel vehicles in China: The case of EV," Energy Policy, vol. 39 (11), no. 11, pp. 7015-7024, Nov. 2011.

[351] Y. Kudoh and R. Motose, "Changes of Japanese consumer preference for electric vehicles," World Electric Vehicle Journal, vol. 4, pp. 880-889, 2010.

[352] J. Shin, C. R. Bhat, D. You, V. M. Garikapati, and R. M. Pendyala, "Consumer preferences and willingness to pay for advanced vehicle technology options and fuel types," Transportation Research Part C: Emerging Technologies, vol. 60, pp. 511-524, 2015.

[353] W. Ko and T.-kyung Hahn, "Analysis of consumer preferences for electric vehicles," IEEE Transactions on Smart Grid, vol. 4, no. 1, pp. 437-442, 2013.

[354] Electric Vehicles Initiative, "Electric Vehicles Initiative ( EVI ), Clean Energy Ministerial. http://www.cleanenergyministerial.org/Our-Work/Initiatives/Electric-Vehicles," 2016.

[355] Y. Zhang, Y. Yu, and B. Zou, "Analyzing public awareness and acceptance of alternative fuel vehicles in China: The case of EV," Energy Policy, vol. 39, no. 11, pp. 7015-7024, Nov. 2011.

[356] R. Daziano and E. Chiew, "Electric vehicles rising from the dead: Data needs for forecasting consumer response toward sustainable energy sources in personal transportation," Energy Policy, vol. 51, pp. 876-894, Dec. 2012.

[357] J. Struben and J. D. Sterman, "Transition challenges for alternative fuel vehicle and transportation systems," Environment and Planning B: Planning and Design, vol. 35, no. 6, pp. 1070-1097, 2008.

[358] O. Egbue and S. Long, "Barriers to widespread adoption of electric vehicles: An analysis of consumer attitudes and perceptions," Energy Policy, vol. 48, pp. 717-729, Sep. 2012.

[359] T. Lieven, "Policy measures to promote electric mobility - A global perspective," Transportation Research Part A: Policy and Practice, vol. 82, pp. 78-93, 2015.

[360] Y. Zhang, Z. S. Qian, F. Sprei, and B. Li, "The impact of car specifications, prices and incentives for battery electric vehicles in Norway: Choices of heterogeneous consumers," Transportation Research Part C: Emerging Technologies, vol. 69, pp. 386-401, 2016.

[361] P. Mau, J. Eyzaguirre, M. Jaccard, C. Collinsdodd, and K. Tiedemann, "The 'neighbor effect': Simulating dynamics in consumer preferences for new vehicle technologies," Ecological Economics, vol. 68(1-2), no. 1-2, pp. 504-516, Dec. 2008.

[362] J. Axsen, D. C. Mountain, and M. Jaccard, "Combining stated and revealed choice research to simulate the neighbor effect: The case of hybrid-electric vehicles," Resource and Energy Economics, vol. 31 (3), no. 3, pp. 221-238, Aug. 2009.

[363] S. Meeran, S. Jahanbin, P. Goodwin, and J. Q. Neto, "When do changes in consumer preferences make forecasts from choice-based conjoint models unreliable?," European Journal of Operational Research, vol. 258 (2), pp. 512-524, 2017. 
[364] M. Maness and C. Cirillo, "Measuring future vehicle preferences: Stated preference survey approach with dynamic attributes and multiyear time frame," Transportation Research Record: Journal of the Transportation Research Board, vol. 2285, pp. 100-109, 2012.

[365] T. R. Hawkins, O. M. Gausen, and A. H. Strømman, "Environmental impacts of hybrid and electric vehicles-a review," The International Journal of Life Cycle Assessment, vol. 17, no. 8, pp. 997-1014, May 2012.

[366] N. D. MacPherson, G. A. Keoleian, and J. C. Kelly, "Fuel Economy and Greenhouse Gas Emissions Labeling for Plug-In Hybrid Vehicles from a Life Cycle Perspective," Journal of Industrial Ecology, vol. 16, no. 5, pp. 761-773, Oct. 2012.

[367] A. Nordelöf, A.-M. Tillman, M. Messagie, and J. Mierlo, "Less or different environmental impact?," in Systems Perspectives in Electricomobility, B. Sanden and P. Wallgren, Eds. Goteborg: Chalmers University of Technology, 2014, pp. 60-75.

[368] T. Batista, F. Freire, and C. M. Silva, "Vehicle environmental rating methodologies: Overview and application to light-duty vehicles," Renewable and Sustainable Energy Reviews, vol. 45, pp. 192-206, May 2015.

[369] J. B. Guinée, Handbook on life cycle assessment: operational guide to the ISO standards. Dordrecht; Boston: Kluwer Academic Publishers, 2002.

[370] A. Nordelöf, M. Messagie, A.-M. Tillman, M. Ljunggren Söderman, and J. Mierlo, "Environmental impacts of hybrid, plug-in hybrid, and battery electric vehicles-what can we learn from life cycle assessment?," The International Journal of Life Cycle Assessment, vol. 19, no. 11, pp. 1866-1890, Aug. 2014.

[371] A. Noshadravan, L. Cheah, R. Roth, F. Freire, L. Dias, and J. Gregory, "Stochastic comparative assessment of life-cycle greenhouse gas emissions from conventional and electric vehicles," The International Journal of Life Cycle Assessment, vol. 20, no. 6, pp. 854-864, Jun. 2015.

[372] P. Girardi, A. Gargiulo, and P. C. Brambilla, "A comparative LCA of an electric vehicle and an internal combustion engine vehicle using the appropriate power mix: the Italian case study," The International Journal of Life Cycle Assessment, vol. 20, no. 8, pp. 1127-1142, Aug. 2015.

[373] R. Garcia, J. Gregory, and F. Freire, "Dynamic fleet-based life-cycle greenhouse gas assessment of the introduction of electric vehicles in the Portuguese light-duty fleet," The International Journal of Life Cycle Assessment, vol. 20, no. 9, pp. 1287-1299, Sep. 2015.

[374] T. R. Hawkins, B. Singh, G. Majeau-Bettez, and A. H. Strømman, "Comparative Environmental Life Cycle Assessment of Conventional and Electric Vehicles," Journal of Industrial Ecology, vol. 17, no. 1, pp. 53-64, Feb. 2013.

[375] C. Samaras and K. Meisterling, "Life Cycle Assessment of Greenhouse Gas Emissions from Plug-in Hybrid Vehicles: Implications for Policy," Environmental Science \& Technology, vol. 42, no. 9, pp. 3170-3176, May 2008.

[376] C. Yang, "A framework for allocating greenhouse gas emissions from electricity generation to plug-in electric vehicle charging," Energy Policy, vol. 60, pp. 722-732, Sep. 2013.

[377] R. Garcia and F. Freire, "Marginal life-cycle greenhouse gas emissions of electricity generation in Portugal and implications for electric vehicles," Resources, vol. 5, no. 4, 2016.

[378] R. T. Doucette and M. D. McCulloch, "Modeling the CO2 emissions from battery electric vehicles given the power generation mixes of different countries," Energy Policy, vol. 39, no. 2, pp. 803-811, Feb. 2011. 
[379] and I. L. A. Mili-Ann M, Tamayao, Jeremy Michalek, Chris Hendrickson, "Regional Variability and Uncertainty of Electric Vehicle Life Cycle CO2 Emissions across the United States (Supporting Information)," vol. 439, pp. 177-179.

[380] Y. Wu et al., "Energy consumption and $\mathrm{CO} 2$ emission impacts of vehicle electrification in three developed regions of China," Energy Policy, vol. 48, pp. 537-550, Sep. 2012.

[381] R. Faria, P. Marques, P. Moura, F. Freire, J. Delgado, and A. T. Almeida, "Impact of the electricity mix and use profile in the life-cycle assessment of electric vehicles," Renewable and Sustainable Energy Reviews, vol. 24, pp. 271-287, Aug. 2013.

[382] S. Soimakallio, J. Kiviluoma, and L. Saikku, "The complexity and challenges of determining GHG (greenhouse gas) emissions from grid electricity consumption and conservation in LCA (life cycle assessment) - A methodological review," Energy, vol. 36, no. 12, pp. 6705-6713, Dec. 2011.

[383] S. Rangaraju, L. Vroey, M. Messagie, J. Mertens, and J. Mierlo, "Impacts of electricity mix, charging profile, and driving behavior on the emissions performance of battery electric vehicles: A Belgian case study," Applied Energy, vol. 148, pp. 496-505, Jun. 2015.

[384] C. G. Hoehne and M. Chester, "Optimizing plug-in electric vehicle and vehicle-to-grid charge scheduling to minimize carbon emissions," Energy, vol. 115, pp. 646-657, Nov. 2016.

[385] K. Hedegaard, H. Ravn, N. Juul, and P. Meibom, "Effects of electric vehicles on power systems in Northern Europe," Energy, vol. 48, no. 1, pp. 356-368, Dec. 2012.

[386] B. Tarroja, J. D. Eichman, L. Zhang, T. M. Brown, and S. Samuelsen, "The effectiveness of plug-in hybrid electric vehicles and renewable power in support of holistic environmental goals: Part 1 - Evaluation of aggregate energy and greenhouse gas performance," Journal of Power Sources, vol. 257, pp. 461-470, Jul. 2014.

[387] D. Dallinger, S. Gerda, and M. Wietschel, "Integration of intermittent renewable power supply using grid-connected vehicles - A 2030 case study for California and Germany," Applied Energy, vol. 104, pp. 666-682, Apr. 2013.

[388] C. Camus, T. Farias, and J. Esteves, "Potential impacts assessment of plug-in electric vehicles on the Portuguese energy market," Energy Policy, vol. 39, no. 10, pp. 5883-5897, Oct. 2011.

[389] R. McCarthy and C. Yang, "Determining marginal electricity for near-term plug-in and fuel cell vehicle demands in California: Impacts on vehicle greenhouse gas emissions," Journal of Power Sources, vol. 195, no. 7, pp. 2099-2109, Apr. 2010.

[390] A. Pina, P. Baptista, C. Silva, and P. Ferrão, "Energy reduction potential from the shift to electric vehicles: The Flores island case study," Energy Policy, vol. 67, pp. 37-47, Apr. 2014.

[391] R. Garcia, F. Freire, and R. Clift, "Effects on Greenhouse Gas Emissions of Introducing Electric Vehicles into an Electricity System with Large Storage Capacity," Journal of Industrial Ecology, Apr. 2017.

[392] T. Yuksel, M.-A. M. Tamayao, C. Hendrickson, I. M. L. Azevedo, and J. J. Michalek, "Effect of regional grid mix, driving patterns and climate on the comparative carbon footprint of gasoline and plug-in electric vehicles in the United States," Environmental Research Letters, vol. 11, no. 4, pp. 1-13, Apr. 2016.

[393] T. Yuksel and J. J. Michalek, "Effects of Regional Temperature on Electric Vehicle Efficiency, Range, and Emissions in the United States," Environmental Science \& Technology, vol. 49, no. 6, pp. 3974-3980, Mar. 2015. 
[394] J. Archsmith, A. Kendall, and D. Rapson, "From Cradle to Junkyard: Assessing the Life Cycle Greenhouse Gas Benefits of Electric Vehicles," Research in Transportation Economics, vol. 52, pp. 72-90, Oct. 2015.

[395] G. N. Correia, T. P. Batista, S. S. Marques, and C. M. Silva, "How car material life-cycle emissions are considered in environmental rating methodologies? Suggestion of expedite models and discussion," Renewable and Sustainable Energy Reviews, vol. 38, pp. 20-35, Oct. 2014.

[396] B. Li, X. Gao, J. Li, and C. Yuan, "Life Cycle Environmental Impact of High-Capacity Lithium Ion Battery with Silicon Nanowires Anode for Electric Vehicles," Environmental Science \& Technology, vol. 48, no. 5, pp. 3047-3055, Mar. 2014.

[397] J. Peters, D. Buchholz, S. Passerini, and M. Weil, "Life cycle assessment of sodium-ion batteries," Energy Environ. Sci., vol. 9, no. 5, pp. 1744-1751, 2016.

[398] D. A. Notter et al., "Contribution of Li-Ion Batteries to the Environmental Impact of Electric Vehicles," Environmental Science \& Technology, vol. 44, no. 17, pp. 6550-6556, Sep. 2010.

[399] G. Majeau-Bettez, T. R. Hawkins, and A. H. Strømman, "Life cycle environmental assessment of lithium-ion and nickel metal hydride batteries for plug-in hybrid and battery electric vehicles.," Environmental science \& technology, vol. 45, no. 10, pp. 4548-54, May 2011.

[400] L. A.-W. Ellingsen, G. Majeau-Bettez, B. Singh, A. K. Srivastava, L. O. Valøen, and A. H. Strømman, "Life Cycle Assessment of a Lithium-Ion Battery Vehicle Pack," Journal of Industrial Ecology, vol. 18, no. 1, pp. 113-124, Feb. 2014.

[401] M. Zackrisson, L. Avellán, and J. Orlenius, "Life cycle assessment of lithium-ion batteries for plug-in hybrid electric vehicles - Critical issues," Journal of Cleaner Production, vol. 18, no. 15, pp. 1519-1529, Nov. 2010.

[402] P. Marques, R. Garcia, L. Kulay, and F. Freire, "Life-cycle assessment of electric vehicle batteries - LiMn2O4 versus LiFePO4," in Energy for Sustainability 2015 - Designing for People and the Planet, 2015.

[403] J. F. Peters, M. Baumann, B. Zimmermann, J. Braun, and M. Weil, "The environmental impact of Li-lon batteries and the role of key parameters - A review," Renewable and Sustainable Energy Reviews, vol. 67, pp. 491-506, Jan. 2017.

[404] S. A. Miller and G. A. Keoleian, "Framework for Analyzing Transformative Technologies in Life Cycle Assessment," Environmental Science \& Technology, vol. 49, no. 5, pp. 3067-3075, Mar. 2015.

[405] M. L. Söderman, D. Kushnir, and B. Sandén, "Will metal scarcity limit the use of electric vehicles?," in Systems Perspectives in Electricomobility, B. Sandén and P. Wallgren, Eds. Goteborg: Chalmers University of Technology, 2014, pp. 76-89.

[406] R. Faria et al., "Primary and secondary use of electric mobility batteries from a life cycle perspective," Journal of Power Sources, vol. 262, pp. 169-177, 2014.

[407] L. Ahmadi, S. B. Young, M. Fowler, R. A. Fraser, and M. A. Achachlouei, "A cascaded life cycle: reuse of electric vehicle lithium-ion battery packs in energy storage systems," The International Journal of Life Cycle Assessment, vol. 22, no. 1, pp. 111-124, Jan. 2017.

[408] J. J. Bogardi et al., "Water security for a planet under pressure: interconnected challenges of a changing world call for sustainable solutions," Current Opinion in Environmental Sustainability, vol. 4, no. 1, pp. 35-43, Feb. 2012. 
[409] K. Richa, C. W. Babbitt, N. G. Nenadic, and G. Gaustad, "Environmental trade-offs across cascading lithium-ion battery life cycles," The International Journal of Life Cycle Assessment, vol. 22, no. 1, pp. 66-81, Jan. 2017.

[410] R. Frischknecht and K. Flury, "Life cycle assessment of electric mobility: Answers and challenges-Zurich, April 6, 2011," International Journal of Life Cycle Assessment, vol. 16, pp. 691-695, 2011.

[411] R. Garcia and F. Freire, "A review of fleet-based life-cycle approaches focusing on energy and environmental impacts of vehicles," Renewable and Sustainable Energy Reviews, 2017.

[412] R. Garcia, "Dynamic Fleet-Based Life-Cycle Assessment: Adressing Environmental Consequences of the Introduction of Electric Vehicles in Portugal," Ph.D thesis, University of Coimbra, Coimbra, Portugal, 2016.

[413] D. F. Vivanco, J. Freire-González, R. Kemp, and E. Voet, "The Remarkable Environmental Rebound Effect of Electric Cars: A Microeconomic Approach," Environmental Science \& Technology, vol. 48, no. 20, pp. 12063-12072, Oct. 2014.

[414] United Nations, "Report of the world commission on environment and development: our common future," 1987.

[415] H. E. Daly, Ecological economics and sustainable development, selected essays of Herman Daly. Edward Elgar Publishing, 2007.

[416] B. Tokar, R. Smolker, B. Tokar, A. Petermann, E. Hernandez, and J. Thomas, "The real cost of agrofuels: impacts on food, forests, peoples and the climate," 2007.

[417] Y. Chisti, "Biodiesel from microalgae," Biotechnology Advances, vol. 25, no. 3, pp. 294-306, 2007.

[418] L. Brennan and P. Owende, "Biofuels from microalgae - A review of technologies for production, processing, and extractions of biofuels and co-products," Renewable and Sustainable Energy Reviews, vol. 14, pp. 557-577, 2010.

[419] J. Sheehan, T. Dunahay, J. Benemann, and P. Roessler, A look back at the U.S. Department of Energy's Aquatic Species program: biodiesel from algae. National Renewable Energy Laboratory, 1998.

[420] A. Aden et al., "Lignocellulosic biomass to ethanol process design and economics utilizing cocurrent dilute acid prehydrolysis and enzymatic hydrolysis for corn stover," National Renewable Energy Laboratory, Golden, Colorado (USA), 2002.

[421] “Oil price." [Online]. Available: http://www.oil-price.net/. [Accessed: Jul-2017].

[422] L. A. Ribeiro, P. Pereira da Silva, L. Ribeiro, and F. L. Dotti, "Modelling the impacts of policies on advanced biofuel feedstocks diffusion," Journal of Cleaner Production, vol. 142, pp. 24712479, 2017.

[423] J. Malça and F. Freire, "Renewability and life-cycle energy efficiency of bioethanol and bioethyl tertiary butyl ether (bioETBE): Assessing the implications of allocation," Energy, vol. 31, no. 15, pp. 3362-3380, 2006.

[424] A. K. Petersen Raymer, "A comparison of avoided greenhouse gas emissions when using different kinds of wood energy," Biomass and Bioenergy, vol. 30, no. 7, pp. 605-617, 2006. 
[425] É. G. Castanheira and F. Freire, "Environmental life cycle assessment of biodiesel produced with palm oil from Colombia," International Journal of Life Cycle Assessment, vol. 22, no. 4, pp. 587-600, 2017.

[426] D. Tonini, L. Hamelin, and T. F. Astrup, "Environmental implications of the use of agroindustrial residues for biorefineries: application of a deterministic model for indirect land-use changes," GCB Bioenergy, vol. 8, no. 4, pp. 690-706, 2016.

[427] É. G. Castanheira, R. Grisoli, S. Coelho, G. Anderi da Silva, and F. Freire, "Life-cycle assessment of soybean-based biodiesel in Europe: comparing grain, oil and biodiesel import from Brazil," Journal of Cleaner Production, vol. 102, pp. 188-201, 2015.

[428] D. F. Correa, H. L. Beyer, H. P. Possingham, S. R. Thomas-Hall, and P. M. Schenk, "Biodiversity impacts of bioenergy production: Microalgae vs. first generation biofuels," Renewable and Sustainable Energy Reviews, vol. 74, no. 2016, pp. 1131-1146, 2017.

[429] V. Mathioudakis, P. W. Gerbens-Leenes, T. H. Meer, and A. Y. Hoekstra, "The water footprint of second-generation bioenergy: A comparison of biomass feedstocks and conversion techniques," Journal of Cleaner Production, vol. 148, pp. 571-582, 2017.

[430] C. Caldeira et al., "Water footprint profile of virgin and waste cooking oils: assessing freshwater degradation and comparing the WSI and the AWARE methods to address scarcity impacts," in SETAC Europe 22nd LCA Case Study Symposium, 2016.

[431] L. Elghali, R. Clift, P. Sinclair, C. Panoutsou, and A. Bauen, "Developing a sustainability framework for the assessment of bioenergy systems," Energy Policy, vol. 35, no. 12, pp. 60756083, 2007.

[432] J. Dauber and A. Bolte, "Bioenergy: Challenge or support for the conservation of biodiversity?," GCB Bioenergy, vol. 6, no. 3, pp. 180-182, 2014.

[433] É. G. Castanheira, H. Acevedo, and F. Freire, "Greenhouse gas intensity of palm oil produced in Colombia addressing alternative land use change and fertilization scenarios," Applied Energy, vol. 114, pp. 958-967, 2014.

[434] É. G. Castanheira and F. Freire, "Greenhouse gas assessment of soybean production: Implications of land use change and different cultivation systems," Journal of Cleaner Production, vol. 54, pp. 49-60, 2013.

[435] M. Brandão, L. Milà i Canals, and R. Clift, "Soil organic carbon changes in the cultivation of energy crops: Implications for GHG balances and soil quality for use in LCA," Biomass and Bioenergy, vol. 35, no. 6, pp. 2323-2336, 2011.

[436] Z. M. Harris, R. Spake, and G. Taylor, "Land use change to bioenergy: A meta-analysis of soil carbon and GHG emissions," Biomass and Bioenergy, vol. 82, pp. 27-39, 2015.

[437] O. E. Sala et al., "Biodiversity across Scenarios," Ecosystem services and Human well-being: Scenarios, vol. 2, pp. 271-280, 2005.

[438] Committee on U.S.-China Cooperation on Electricity from Renewable Resources, N. R. Council, C. A. of Sciences, and C. A. of Engineering, The Power of Renewables: Opportunities and Challenges for China and the United States. 2010.

[439] J. Malça, P. Marques, L. Serrano, E. Castanheira, R. Garcia, and F. Freire, "Comparative Wellto-Wheels Assessment of Biodiesel and Fossil Diesel for Heavy Duty Transport in Latin America," in Proceedings of CEM2016 - Mechanical Engineering Conference, 2016. 
[440] World Bank, "How Global Biofuel Expansion Could Affect the Economy, Environment and Food Supply," 2011. .

[441] G. . Schoneveld, L. . German, and E. Nutakor, "Paper Summary - Towards sustainable biofuel development: assessing the local impacts of large-scale foreign land acquisitions in Ghana," World Bank Land Governance Conference, no. April, pp. 1-7, 2010.

[442] L. German and G. Schoneveld, "Social sustainability of EU-approved voluntary schemes for biofuels," Implications for Rural Livelihoods, pp. 1-38, 2011.

[443] K. Obidzinski, R. Andriani, H. Komarudi, and Andrianto, "Environmental and Social Impacts of Oil Palm Plantations and their Implications for Biofuel Production in Indonesia," Ecology \& Society, vol. 17, no. 1, p. 25, 2012.

[444] V. G. . Luz et al., "Migrant labor and wear-out in manual sugarcane harvesting in São Paulo, Brazil [Trabalho e desgaste de migrantes no corte manual de cana de açúcar no Estado de São Paulo, Brasil]," Ciencia e Saude Coletiva, vol. 17, no. 10, pp. 2831-2840, 2012.

[445] C. Du, L. Kulay, O. Cavalett, L. Dias, and F. Freire, "Life cycle assessment addressing health effects of particulate matter of mechanical versus manual sugarcane harvesting in Brazil," The International Journal of Life Cycle Assessment, 2017.

[446] C. G. Duarte, K. Gaudreau, R. B. Gibson, and T. F. Malheiros, "Sustainability assessment of sugarcane-ethanol production in Brazil: A case study of a sugarcane mill in São Paulo state," Ecological Indicators, vol. 30, pp. 119-129, 2013.

[447] P. G. Machado, A. Walter, M. C. Picoli, and C. G. Jo??o, "Potential impacts on local quality of life due to sugarcane expansion: a case study based on panel data analysis," Environment, Development and Sustainability, pp. 1-24, 2016.

[448] J. Domac, "Bioenergy and job generation," Unasylva, vol. 53, no. 211, pp. 18-19, 2002.

[449] J. Guinee et al., “Life Cycle Assessment: Past ," vol. 45, no. 1, pp. 90-96, 2011.

[450] T. E. Swarr et al., "Environmental life-cycle costing: A code of practice," International Journal of Life Cycle Assessment, vol. 16, no. 5, pp. 389-391, 2011.

[451] UNEP Setac Life Cycle Initiative, Guidelines for Social Life Cycle Assessment of Products, vol. 15, no. 2. 2009.

[452] United Nations Environmental Program (UNEP), Towards a Life Cycle Sustainability A ssessment: Making informed choices on products. 2011.

[453] M. C. McManus and C. M. Taylor, "The changing nature of life cycle assessment," Biomass and Bioenergy, vol. 82, pp. 13-26, 2015.

[454] Y. Manik, J. Leahy, and A. Halog, "Social life cycle assessment of palm oil biodiesel: A case study in Jambi Province of Indonesia," International Journal of Life Cycle Assessment, vol. 18, no. 7 , pp. 1386-1392, 2013.

[455] C. Macombe, P. Leskinen, P. Feschet, and R. Antikainen, "Social life cycle assessment of biodiesel production at three levels: A literature review and development needs," Journal of Cleaner Production, vol. 52, pp. 205-216, 2013.

[456] J. Ren, A. Manzardo, A. Mazzi, F. Zuliani, and A. Scipioni, "Prioritization of bioethanol production pathways in China based on life cycle sustainability assessment and multicriteria 
decision-making," The International Journal of Life Cycle Assessment, vol. 20, no. 6, pp. $842-$ 853, 2015.

[457] B. Notarnicola, S. Sala, A. Anton, S. J. McLaren, E. Saouter, and U. Sonesson, "The role of life cycle assessment in supporting sustainable agri-food systems: A review of the challenges," Journal of Cleaner Production, vol. 140, pp. 399-409, 2017.

[458] J. Malça and F. Freire, "Life-cycle studies of biodiesel in Europe: A review addressing the variability of results and modeling issues," Renewable and Sustainable Energy Reviews, vol. 15, no. 1, pp. 338-351, Jan. 2011.

[459] C. Caldeira, J. Queirós, A. Noshadravan, and F. Freire, "Incorporating uncertainty in the Life Cycle Assessment of biodiesel from Waste Cooking Oil addressing different collection systems," Resources, Conservation and Recycling, 2016.

[460] F. Reale, M. Cinelli, and S. Sala, "Towards a research agenda for the use of LCA in the impact assessment of policies," International Journal of Life Cycle Assessment, pp. 1-5, 2017.

[461] I. Kluts, B. Wicke, R. Leemans, and A. Faaij, "Sustainability constraints in determining European bioenergy potential: A review of existing studies and steps forward," Renewable and Sustainable Energy Reviews, vol. 69, pp. 719-734, 2017.

[462] A. Tsoukiàs, "On the concept of decision aiding process: An operational perspective," Annals of Operations Research, vol. 154, no. 1, pp. 3-27, 2007. 